\title{
THE HUMAN MICROBIOME AND PROBIOTICS: IMPLICATIONS FOR PEDIATRICS
}

\author{
Michael H. Hsieh, M.D., Ph.D1 and James Versalovic, M.D., Ph.D.2,* \\ ${ }^{1}$ Division of Pediatric Urology, Texas Children's Hospital and Scott Department of Urology, Baylor \\ College of Medicine, Houston, TX \\ 2 Departments of Pathology, Texas Children's Hospital and Baylor College of Medicine, Houston, \\ TX
}

\section{Abstract}

The "human super-organism" refers to the human body and the massive numbers of microbes which dwell within us and on the skin surface. Despite the large numbers of microbes co-existing within the human body, humans including infants and children achieve a physiologic state of equilibrium known as health in the context of this microbial world. These key concepts suggest that many individual members of the human microbiome, including bacterial and fungal species, confer different benefits on the human host. Probiotics, or beneficial microbes, may modulate immune responses, provide key nutrients, or suppress the proliferation and virulence of infectious agents. The human microbiome is in fact dynamic and often in flux, which may be indicative of the continuous interplay among commensal microbes, pathogens, and the human host. In this article we review the state-of-the-art regarding probiotics applications to prevent or treat diseases of the pediatric gastrointestinal and genitourinary systems. Additionally, probiotics may regulate local and systemic immunity, thereby reducing allergic disease severity and susceptibilities of infants and children to allergies and atopic diseases. In summary, beneficial microbes offer promising alternatives for new strategies in therapeutic microbiology with implications for different subspecialties within pediatrics. Instead of simply trying to counteract microbes with vaccines and antibiotics, a new field of medical microbiology is emerging that strives to translate human microbiome research into new probiotics strategies for promotion of health and prevention of disease in children.

\section{Introduction}

\begin{abstract}
Abundant communications and "microverses" are being transmitted between diverse microbial communities and different cell types in disparate locations within the human body. Various examples of welcome and unwelcome partners and intruders have been documented in the medical and scientific literature. Complex eukaryotes that are in reality arthropods, instead of microbes, co-exist within human hosts. Demodex mites inhabit the follicles of eyelashes and feed on skin cells, and Pediculus humanus capitis, the head louse, subsists on human blood and cements its nits to hair (Figure 1). Eukaryotic microbes such as fungi include
\end{abstract}

\footnotetext{
*Corresponding author: James Versalovic, M.D., Ph.D., Department of Pathology, Texas Children's Hospital, 6621 Fannin MC 1-2261, Houston, TX 77030, Phone: 832-824-2213, Fax: 832-825-0164, jamesv@bcm.edu.

Disclosures: Dr. Versalovic has received unrestricted research support from Biogaia AB, Stockholm, Sweden; and has received honoraria from Group Danone, Paris, France.

Publisher's Disclaimer: This is a PDF file of an unedited manuscript that has been accepted for publication. As a service to our customers we are providing this early version of the manuscript. The manuscript will undergo copyediting, typesetting, and review of the resulting proof before it is published in its final citable form. Please note that during the production process errors may be discovered which could affect the content, and all legal disclaimers that apply to the journal pertain.
} 
Epidermophyton and Trichophyton, the causative agents for athlete's foot, ringworm, and related infections of the genitalia and scalp. Prokarotic microbes or bacteria are single-celled microorganisms which inhabit the skin, alimentary, and genitourinary tracts. Passengers include viruses such as herpes simplex virus (HSV), which infect and lie dormant in nerve cells, and so-called "fossil viruses", which integrated into the human genome long ago and account for approximately $7 \%$ of our genetic composition ${ }^{1}$, 2 . By some estimates, 100 trillion microbes live within each human individual3, 4 . The perpetual interactions among these microbes and our bodies may, at least partly, determine whether individuals remain healthy or become susceptible to different diseases including immune-mediated disorders and infections. For example, commensal bacteria in the gut may contribute to vitamin production and absorption, metabolism of proteins and bile acids, fermentation of dietary carbohydrates, and prevention of pathogen overgrowth ${ }^{5}$. Furthermore, investigators have postulated roles for microbes in human diseases not traditionally associated with infectious etiologies, such as cancer $^{6}$, autoimmune disorders ${ }^{7}$, chronic pain states ${ }^{8,}{ }^{9}$, and inflammatory bowel disease ${ }^{10}$.

Humans beings have consumed bacterial-augmented foods since approximately 3500 B.C., when the Sumerians developed cheeses ${ }^{11}$. Another example of historical and religious significance was Abraham's ingestion of milk and curds as documented in biblical history in approximately 2000 B.C. The Celts and Huns have been credited with the development of kefir, a fermented milk product ${ }^{12}$. Fermented foods were further refined by monks during the Middle Ages. In the past century, steady advances in food science and the food industry have contributed to the foundation of knowledge in the fields of beneficial microbes, lactic acid bacteria, fermented foods and microbe-supplemented food products. However, only in the past 20 years have we witnessed publications of studies exploring biomedical applications of probiotics and mechanisms of probiosis in the context of mammalian and human biology ${ }^{13}$.

Here, we review ongoing efforts to comprehensively characterize the human microbiome, the collection of all bacterial genomes inhabiting the human host, and how this work will identify probiotics. Probiotics are "live microorganisms which when administered in adequate amounts confer a health benefit on the host" ${ }^{14}$. Finally, we will formulate some predictions of how microbiomics and probiotics will impact medical management of various pediatric disorders.

\section{The Indigenous Human Microbiome and Dynamic Fluctuations in Infancy}

The human gastrointestinal tract contains a complex microbiota including between 800 and 1000 bacterial species, with $>60 \%$ and $>80 \%$ of 16 S rDNA sequences representing unknown and nonculturable microbes, respectively, in one landmark metagenomics study of human adults ${ }^{15}$. Even the skin of the human forearm, a region of the body with a less complex microbiota, may foster more than 182 bacterial species ${ }^{16}$. However, human microbial complexity extends beyond species to individual clones or strains, resident viral sequences, and spatial topography of microbial communities. Published studies by Swidsinski et al. ${ }^{17}$, ${ }^{18}$ highlighted the point that specific microbes are not randomly distributed in space, but, instead, microbes are differentially distributed in different locations and subsites within the intestinal tract (Figure 2). Specifically, FISH staining of the human colon revealed that Bacteroides fragilis, Eubacterium rectale, and other bacteria inhabit discrete zones in successive layers within the intestinal lumen ${ }^{17}$. Furthermore, in patients with inflammatory bowel disease, the biofilm mass and relative preponderance of $B$. fragilis was higher than in healthy controls. Similar findings have been reported in the mouse alimentary tract 18 , suggesting that compartmentalization of organ-specific microbial communities may be a conserved feature among mammalian species. Mechanical forces and physiologic processes such as excretion may affect the relative composition of the human microbiota. For example, the mucosa-associated microbiota of the human gastrointestinal tract differs from the community recovered from feces ${ }^{19}$. These differences are likely due to effects of intestinal 
peristalsis and relative propensities for different microbes to adhere to the epithelium or colonize mucosa-associated regions such as the mucus layer adjacent to the mucosa. Hence, the microbial ecology of humans is intricate not only because of the sheer numbers of represented species, but also topographical differences in species distribution within different organ systems and mucosal surfaces. To help dissect the microbial complexity underscored by these and other metagenomics studies, the NIH began a Roadmap Initiative in 2007 in the form of the Human Microbiome Project (HMP). The HMP seeks to "generate resources enabling comprehensive characterization of the human microbiota and analysis of its role in human health and disease" ${ }^{20}$. Program initiatives for the HMP include development of a reference set of microbial genome sequences and preliminary characterization of the human microbiome; determination of the relationships between disease and changes in the human microbiome; development of new technologies, including novel tools for computational analysis; establishment of data analysis and coordinating centers as well as a resource repository for organisms and their genomes, and exploration of the ethical, social, and legal implications of the HMP itself. Initial efforts have been directed towards sequencing the genomes of a reference set of 200 microbes isolated from the human body, recruitment of healthy donors for sampling from a set of body regions, and preliminary $16 \mathrm{~S}$ rDNA gene metagenomic sequence analyses to estimate the complexity of the microbiota at these body sites.

Dynamic fluctuations and microbial population shifts within the human microbiome likely occur in the neonatal period and infancy, and in association with changes in nutritional status or exposure to antibiotics. Palmer et al. demonstrated that the composition and temporal patterns of intestinal microbiota varied widely among infants, with complex communities existing by one week of age ${ }^{21}$. Despite temporal variation, distinct features of each infant's microbial community were recognizable for months at a time. Furthermore, 3 out of 22 level 2 prokMSA divisions (phylogenetic classifications) dominated the human intestine in this study, namely Gram-positive Bacteria, Flexibacter-Cytophaga-Bacteroides, and Proteobacteria ${ }^{21}$. Dizygotic twin analysis showed parallel temporal patterns suggestive of environmental influences. At the end of the first year of life, each infant's gut bacterial population achieves adult-like complexity and a state of relative equilibrium. Finally, birth by caesarean section and neonatal antibiotic utilization seem to profoundly modulate early intestinal colonization patterns, with delays of colonization being a hallmark effect (Figure 3). These issues beg the question whether differences in microbial composition or complexity early in life affect subsequent disease susceptibility.

The diversity and composition of the human microbiome influences birth outcomes prior to parturition. DiGiulio et al. reported that a complex microbiota in the amniotic fluid of pregnant women was associated with preterm labor ${ }^{22}$. In fact the positive predictive value of bacterial rDNA PCR for preterm delivery was $100 \%$. Hence, human bacterial communities profoundly influence human health throughout life. The kinetics of bacterial colonization in the neonate are further complicated by passage of commensal bacteria such as Bifidobacterium from maternal blood to human breast milk, and ultimately the infant gastrointestinal $\operatorname{tract}^{23}$. Although a controversial concept in maternal-fetal medicine and pediatrics, bacterial components may be translocated from mother to infant through maternal mononuclear cells which may prime the developing infant immune system to appropriately respond to commensal and pathogenic bacteria. Clearly, more data and follow-up studies are needed to explain the patterns of microbial colonization and effects on development of immunity during infancy and early childhood. 


\section{The Probiotic Concept}

"A reader ...may be surprised by my recommendation to absorb large quantities of microbes, as a general belief is that microbes are harmful. This belief is erroneous. There are many useful microbes, amongst which the lactic bacilli have an honorable place." 24

The probiotic concept was described above in a treatise by Elie Metchinokoff, noted immunologist, microbiologist and Nobel Laureate, entitled On the Prolongation of Life and published in $1907^{24}$. However, this concept essentially lay dormant during the twentieth century and throughout the "golden era" of antibiotics and vaccines. With the rise in the number of multidrug resistant pathogens and the recognition of the role that the human microbiota plays in health and disease, a recent expansion of interest in probiotics has been generated. This phenomenon is apparent in both the numbers of probiotic products being marketed to consumers as well as the increased amount of scientific research occurring in probiotics. Evidence for the renewed interest in probiotics exists in the revival of the probiotic concept in the past two decades by Roy Fuller ${ }^{25}$ and a group of scientists working on behalf of the World Health Organization ${ }^{14}$. Probiotics are nonpathogenic, viable microbes that exert a variety of beneficial effects on the host when consumed in adequate amounts. Beneficial effects are broadly defined by design and may include anti-pathogenic effects, immunomodulatory features, regulation of cell proliferation, the ability to promote normal physiologic development of the mucosal epithelium, and enhancement of human nutrition. A prime example of a probiotic effect delivered by yogurts containing beneficial bacteria is the provision of bacteriaderived lactase to the gastrointestinal tracts of lactase-deficient human individuals. Commensal microbes may actively prevent gastrointestinal infections through production of antimicrobial factors, stimulation of the host immune system, or competition with pathogens for nutrients or host binding sites (Figure 4).

Conversely, immunomodulatory functions of probiotics in the gastrointestinal tract may dampen pathologic host responses such as inflammation, loss of electrolytes and water (diarrhea), and abdominal pain. Commensal bacteria may promote intestinal barrier functions by inducing mucin production and decreasing permeability within the intestinal epithelium 26 , 27. Finally, probiotics produce amino acids, polyphenols, vitamins, and other compounds of nutritive value to the host. The multi-faceted benefits of probiotics have stimulated the food industry to advance the science of food microbiology and maintain bacterial populations in dairy products and other dietary formulations.

Probiotics may be derived from the autochthonous (indigenous) microbiota or the allochthonous (transient) microbiota. The food industry and food science research have generated a variety of allochthonous or autochthonous microbes that may be selected for superior qualities in terms of propensity for large-scale culture and fermentation, enhanced survival in different food formulations, or relative ease of preservation and manipulation. The indigenous microbiota provides an attractive source of beneficial microbes because these microorganisms may have enhanced abilities to persist and thrive in their species of origin (e.g. Homo sapiens). Only restricted subsets of species in individual genera (e.g. Lactobacillus) are considered indigenous to individual host species considered otherwise as distinct mammalian ecosystems. Knowledge gained from advances in human microbiome research will likely provide fertile opportunities to identify novel classes or strains of beneficial microbes. Beneficial microbes may thrive if specific nutrients or carbohydrates are present in the local environment. Prebiotics are non-digestible carbohydrates that selectively stimulate the proliferation of specific genera of beneficial bacteria in the gut, thereby providing indirect benefits to the host. Two categories of prebiotics include galacto-oligosaccharides, found in breast milk, and fructo-oligosaccharides such as inulin, found in vegetables ${ }^{28}$. Prebiotics may 
be combined with probiotics in clinical studies, and these combinations are referred to as synbiotics.

Before reviewing the medical literature with respect to probiotics and pediatrics, it is important to recognize that well-designed clinical studies should specify the precise nature of the probiotic strain(s). Additionally, the dosage and mode of administration should be adequately justified. As will be discussed later in this review, different strains within the same species can have markedly different and opposing biological functions or effects. Unfortunately, many commercial preparations may not meet minimum criteria of quality and specifications. Finally, many studies have examined complex strain combinations and utilized different clinical endpoints for the same diseases, further complicating interpretations and comparisons of findings generated by clinical trials.

\section{Probiotics for Gastrointestinal Health and Disease}

Deliberate and sustained remodeling of gastrointestinal microbial communities has been demonstrated by multiple studies deploying different probiotics or prebiotics formulations. For example, exogenous oral administration of probiotic Bifidobacterium species resulted in greater numbers of enteric Bifidobacterum in infants ${ }^{29}$. Likewise, oral ingestion of L. reuteri has been shown to result in colonization of the ileum in healthy individuals ${ }^{30}$. L. reuteri and other lactobacilli are found in multiple mammalian and bird species, suggesting an ancient evolutionary niche for this commensal species ${ }^{31}$. In addition to direct administration of beneficial microbes, oral ingestion of prebiotics (oligofructose and inulin) increased commensal populations of Eubacterium and Bifidobacterium species in the proximal and distal gut, as well as Lactobacillus quantities in the proximal gut ${ }^{32}$. In another study relevant to pediatric practice, prebiotics-fortified milk has been reported to increase L. acidophilus levels in the infant gut ${ }^{33}$.

Probiotics have been applied successfully in the context of gastroduodenal disease, specifically Helicobacter pylori infection. Multiple clinical trials demonstrated that a variety of probiotic strains can improve tolerability of $H$. pylori eradication therapy ${ }^{34-38}$. Furthermore, one randomized, double blind trial of children infected with $H$. pylori showed that L. casei DN-114 001 supplementation of triple therapy (omeprazole, amoxicillin, and clarithromycin) resulted in greater $H$. pylori clearance rates ${ }^{39}$. In the context of gastric infections due to $H$. pylori, it appears that probiotics may serve a dual role to either improve patient compliance to multiagent treatment regimens or actually help eliminate the pathogen.

Different probiotic formulations have been successfully applied to help prevent or treat patients with acute gastroenteritis. Antibiotics, in contrast, have limited utility for the treatment of gastroenteritis in general. Probiotics such as L. rhamnosus GG, L. reuteri, Bifidobacterium, and the yeast " $S$. boulardi" have also been reported to improve diarrhea and other symptoms of acute gastroenteritis. Weizman et al. reported that infants fed infant formula supplemented with B. lactis $\mathrm{Bb} 12$ or L. reuteri daily for 12 weeks had a lower incidence of enteric infections and shorter episodes of diarrheal disease, with no discernible effect on respiratory

illnesses ${ }^{40}$. In addition to disease prevention, L. reuteri reduced the duration of watery diarrhea in hospitalized children in a placebo-controlled trial ${ }^{41}$. A randomized, placebo-controlled study of " $S$. boulardii" demonstrated diminished symptom duration in children with acute diarrhea 42 . One placebo-controlled trial of children with rotavirus gastroenteritis demonstrated that $L$. reuteri colonized the gastrointestinal tract and shortened the duration of watery diarrhea from 2.5 to 1.9 days ${ }^{43}$. Another pediatric trial compared 3 different probiotic regimens in rotavirusinfected patients and showed that administration of $L$. rhamnosus GG resulted in the shortest duration of diarrhea and enhancement of rotavirus-specific IgA responses ${ }^{44}$. A randomized, placebo-controlled clinical trial in Peru examined whether L. rhamnosus GG could prevent 
diarrhea in undernourished children ${ }^{45}$. Interestingly, the incidence of diarrhea was decreased in children that received $L$. rhamnosus GG, but duration of symptoms was unchanged. Another randomized, placebo-controlled Peruvian clinical trial examined the ability of L. rhamnosus GG to ameliorate acute diarrhea, and reported no reduction in duration of disease ${ }^{46}$.

Furthermore, a randomized, placebo-controlled trial of L. rhamnosus 19070-2 and L. reuteri DSM 12246 in Danish day-care children with mild diarrhea showed diminished symptom duration from 116 to 76 hours ${ }^{47}$. The administration of probiotics, and in particular lactobacilli, appears to be a useful strategy for prevention and treatment of gastroenteritis. The data are more robust for disease prevention in the context of pediatric acute gastroenteritis, but data from several trials do suggest that specific probiotic strains may be useful for treatment of acute gastrointestinal infections (www.cochrane.org) (Figure 5). Specific probiotics formulations may reduce disease duration and possibly alleviate the risk of life-threatening complications of acute gastroenteritis such as dehydration, especially in young children.

Antibiotics may fundamentally alter microbial populations in the gastrointestinal tract, possibly resulting in antimicrobial-associated diarrhea or colitis. Probiotics have been investigated for their abilities to alleviate antimicrobial-associated disease including Clostridium difficile infection. L. rhamnosus GG has been shown to reduce the incidence, but not severity, of antibiotic-associated diarrhea in children treated for respiratory infections ${ }^{48}$. In another randomized, placebo-controlled trial of children with antibiotic-associated diarrhea, $L$. rhamnosus GG decreased stool frequency and increased stool consistency ${ }^{49}$. An Italian pediatric study of a $L$. sporogenes/fructo-oligosaccharides (synbiotics) combination demonstrated a reduced incidence and duration of antibiotic-associated diarrhea ${ }^{50}$ Multiple clinical trials have reported that "S. boulardii" can prevent antibiotic-associated diarrhea in children ${ }^{51-56}$. Finally, a randomized, placebo-controlled study has shown that " $S$.

boulardii" in combination with standard antibiotics reduces the risk of recurrent $C$. difficileassociated disease as compared to standard antibiotics alone ${ }^{57}$. Such studies raise intriguing questions regarding potential combinations of antibiotics and probiotics for human disease, even in the context of antibiotic-associated disease. In summary, the data for antimicrobialassociated diarrhea in pediatric patients appears to be promising, but intention-to-treat data thus far lack significance (www.cochrane.org) (Figure 5).

Acute gastroenteritis may be a predisposing factor for chronic gastrointestinal complications such as post-infectious irritable bowel syndrome (IBS) ${ }^{58}$. Evidence suggests that altered intestinal microbiota is a hallmark of IBS, with increased proportions of potential pathogens such as clostridial species 59, 60. Clinical trials including a variety of probiotic strains have been performed in the context of treating a chronic condition such as IBS. Several studies have documented modulation of gut microbiota with probiotic administration. In a randomized, placebo-controlled trial, patients receiving a multispecies probiotics formulation $(L$. rhamnosus GG, L. rhamnosus Lc705, Propionibacterium freudenreichii ssp. shermanii JS, and B. animalis ssp. lactis Bb12) showed improved abdominal distension and pain, as well as stabilization of the intestinal microbiota ${ }^{61}$. Further testing of this strain combination in two subsequent studies confirmed symptomatic improvement ${ }^{62}$ and showed evidence of a stable microbiota except for the genus Bifidobacterium, which increased among patients in the placebo arm and decreased among patients in the probiotics arm ${ }^{63}$. A placebo-controlled study of L. plantarum DSM 9843 demonstrated improvements in flatulence and stable fecal enterococcal populations among patients in the probiotics treatment arm, and concomitant increases in fecal enterococcal populations among patients receiving placebo ${ }^{64}$. In a randomized, open label trial of the antibiotic rifaximin versus rifaximin in combination with B. longum W11, patients with IBS receiving combination therapy demonstrated colonization by W11 and improved symptomatology 65 . IBS or disease subsets of IBS may be aggravated by a Th1-mediated response with hallmark Th1-associated pro-inflammatory cytokines. A trial of $L$. salivarius UCC4331 versus B. infantis 35624 showed that at baseline, patients with IBS 
displayed abnormal IL-10/IL-12 ratios, indicative of a Th1-type disease state. Furthermore, patients receiving $B$. infantis displayed greater improvements in symptoms and normalization of IL-10/IL-12 ratios ${ }^{66}$. A separate trial also reported that high dose $\left(\geq 1 \times 10^{8} \mathrm{cfu}\right) \mathrm{B}$. infantis 35624 relieved IBS symptoms ${ }^{67}$. In brief, other probiotic strains that have been tested and reported to provide benefits for adult patients with IBS in different studies include $L$. acidophilus-SDC 2012, $2013^{68}$, B. animalis DN-173 $010^{69}$, B. longum $\mathrm{W} 11$ in combination with the prebiotic Fos Actilight (short chain oligosaccharide) ${ }^{70}$, E. coli $\mathrm{M}-17$ (single arm study) ${ }^{71}$, VSL \#3 (L. casei, L. plantarum, L. acidophilus, L. delbruekii subsp. Bulgaricus, B. longum, B. breve, B. infantis, and Streptococcus salivarius subsp. Thermophilus) ${ }^{72} 73$; and PrescriptAssist, a 30 -strain probiotics combination ${ }^{74}$.

Research results for probiotics in IBS, however, are not uniformly positive. Strains that have been described as ineffective for adult IBS include a 4-strain combination (B. longum LA 101, L. acidophilus LA 102, L. lactis LA 103, and S. thermophilus LA 104) ${ }^{75}$, L. rhamnosus GG $(\mathrm{LGG})^{76}$, and $L$. reuteri ATCC $55730^{77}$. Conflicting findings have been reported for $L$. plantarum $299 \mathrm{~V} 78,79$. One pediatric trial of $L$. rhamnosus $\mathrm{GG}$ reported that abdominal distension was improved, but pain was not ameliorated 80, whereas another pediatric trial of LGG demonstrated symptomatic improvement in children with IBS but not functional abdominal pain disorders ${ }^{81}$. Investigators in trials with negative findings have conjectured that the heterogeneity in disease phenotypes of IBS, i.e., diarrhea- versus constipation-predominant IBS, may account for the variation in reported results. The disease criteria for pediatric functional abdominal pain disorders including IBS continue to be refined and revised as part of the ROME III criteria (e.g., functional abdominal pain, irritable bowel syndrome, functional dyspepsia, abdominal migraine, etc. ${ }^{82}$. Regardless, the variety of probiotic strains that have been evaluated and mixed outcomes makes it difficult to draw definitive conclusions regarding the efficacy of probiotics for pediatric IBS. Besides ameliorating inflammation and improving diarrheal disease phenotypes, probiotics may yield benefits for gastrointestinal disease outcomes if strains are selected for anti-nociceptive features. In fact, modulation of pain receptors by probiotics has been postulated as part of the mechanism for probiotic-induced relief of irritable bowel syndrome 83. This mechanism is consistent with the finding that $L$. reuteri ATCC 55730 proved superior to simethicone in relieving infantile colic, with median crying times of 51 versus 145 minutes/day, respectively ${ }^{84}$. In addition, probiotic lactobacilli seem to improve feeding tolerance and gastric emptying in preterm infants ${ }^{85}$. Probiotics may indeed play a role in modulating the physiology of the enteric nervous system and pain perception, resulting in therapeutic benefits for pediatric IBS and other gastrointestinal disorders.

Necrotizing enterocolitis (NEC) affects many neonates and infants, and provides another significant opportunity for disease prevention or treatment by probiotics in pediatrics. Although aspects of the pathophysiology remain unclear, NEC involves various risk factors including pathogen overgrowth and increased epithelial permeability. A clinical trial of B. lactis demonstrated that probiotic-fed preterm infants exhibited higher Bifidobacterium counts in the stool and diminished intestinal permeability, as compared to infants not receiving probiotics ${ }^{86}$. In a randomized trial of a probiotic mixture (B. infantis, S. thermophilus, and B. bifidus) versus placebo, very low birth weight neonates receiving probiotics featured a lower incidence and severity of $\mathrm{NEC}^{87}$. Another randomized trial of very low birth weight neonates compared a group receiving the combination of $L$. acidophilus and $B$. infantis to a group not receiving any probiotics. This study reported that infants receiving probiotics exhibited reduced incidence and severity of NEC ${ }^{88}$. A case-control study of multi-modal prophylaxis against NEC (breast milk, enteral antibiotics, antifungals, with or without probiotics) demonstrated a benefit for very low birth weight infants whose diets were supplemented with probiotics ${ }^{89}$. An additional case-control study reported that infants receiving $L$. acidophilus and B. infantis had a lower incidence of and mortality from $\mathrm{NEC}^{90}$. On the other hand, a large randomized study 
of $L$. rhamnosus GG versus placebo showed a lack of any discernible benefit in terms of rates of NEC or sepsis for neonates receiving probiotics ${ }^{91}$. The overall conclusions of the Cochrane Database for Systematic Reviews indicate the probiotics have demonstrated efficacy for severe NEC and mortality due to NEC (www.cochrane.org) (Figure 5).

Various other gastrointestinal disorders may provide opportunities for applications of probiotics that will partly depend on advances in human microbiome research programs. Numerous trials have attempted to demonstrate efficacy of probiotics formulations for inflammatory bowel disease (IBD), either Crohn disease or ulcerative colitis. These studies in patient groups with adult or pediatric IBD have yielded disappointing results for the most part. One notable exception is the multi-strain probiotics combination, VSL \#3, that has been applied successfully in the context of adult patients with ulcerative colitis. A number of open label studies have indicated that this 8-strain probiotics combination may relieve arthralgia in patients with ulcerative colitis or Crohn disease ${ }^{92}$ and induce remission in ulcerative colitis93 94. VSL \#3 may alleviate pouchitis, inflammation of the ileal pouch-anal anastomosis in patients with ulcerative colitis, by reducing fungal populations and increasing bacterial diversity in the ileal pouch 95. In a randomized trial, patients with ulcerative colitis who received balsalazide in addition to VSL \#3 featured higher and more rapid remission than patients receiving balsalazide alone ${ }^{96}$. Furthermore, VSL \#3 has been shown in two Italian clinical trials to prevent development of acute pouchitis as well as relapses of chronic pouchitis 97, 98. The punch line is that only this relatively complex probiotics combination, VSL\#3, has demonstrated efficacy in the context of IBD to date in the medical literature. In contrast to the limited successes with maintenance of remission in ulcerative colitis, probiotic agents have not yielded any success in treatment of intestinal inflammation in Crohn disease

(www.cochrane.org) (Figure 5). In addition to IBD, probiotics may ameliorate other forms of colitis. L. acidophilus LA-5 and B. animalis subsp. lactis BB-12 have been reported to improve the disease phenotype of collagenous colitis and associated abnormalities in bowel frequency and stool consistency in post hoc analysis of a randomized, placebo-controlled trial ${ }^{99}$. The probiotics arms of this study, however, failed to demonstrate improvement in the primary endpoint, a reduction in stool frequency per week of $\geq 50 \%$. Additional trials are required to determine the role of probiotics in collagenous colitis. In the context of radiation-induced colitis, probiotics may promote intestinal healing and restitution. Specifically, one placebocontrolled trial of VSL \#3 demonstrated that radiation-associated diarrhea was less severe, bowel movements were decreased, and loperamide consumption was reduced among patients in the probiotics arm ${ }^{100}$.

\section{The Microbiome and Obesity: A Potential Role for Probiotics}

The gut microbiota may ultimately exert effects not only locally within the intestine, but commensal microbes may also confer systemic effects and profoundly influence host metabolism. Modern research techniques such as FISH, flow cytometry, and quantitative PCR have suggested that infants with lower levels of Bifidobacterium and higher numbers of $S$. aureus in their stool are at risk of subsequent obesity ${ }^{101}$. Investigations in mouse models demonstrated that transplantation of microbial communities can transfer propensity for fat deposition, supporting a role for the gut microbiome in the metabolic syndrome ${ }^{102}$. These studies indicate that manipulation of the intestinal microbiota through administration of probiotics may reduce susceptibility to obesity and alter body metabolism in fundamental ways, yielding implications for the practices of pediatric endocrinology, gastroenterology, and nutrition. In fact, mice fed trans-10,cis-12-conjugated linoleic acid-expressing L. plantarum PL62 featured reduced adipose tissue and body weights, as well as serum glucose levels ${ }^{103}$. In brief, probiotics may prove to be useful adjuncts in strategies to alleviate the huge burden of childhood obesity. 


\section{Probiotics for Genitourinary Health and Disease}

In the 1970s, investigators determined that most uropathogens in girls originate in the intestine, ascend along the perineum to the vagina, and then infect the bladder. Some scientists have studied the microbiology of non-pathogenic lactobacilli found in high numbers in the vagina of women with no history of urinary tract infections (UTI), and how the absence of these indigenous microbes may be associated with predisposition to recurrent urinary tract infections (UTIs) ${ }^{104}$. Lactobacilli may provide a bacterial barrier that interferes with the ability of pathogens to colonize the vagina and ascend into the bladder 105. As yet, only one study has suggested how pathogens might displace or eliminate lactobacilli, and this pathogen was a bacteriocin-producing Enterococcus faecium ${ }^{106}$. In addition, no studies have examined how pathogens avoid suppression or elimination by the indigenous microbiota, or whether continual seeding of the bladder from the vagina is a crucial component for development of persistent or recurrent infections. ${ }^{107-109}$ An inordinate number of studies have focused on virulence properties of genitourinary pathogens such as $E$. coli and antibiotic utilization in this context. However, more studies are needed to understand the microbiology, microecology and molecular biology of indigenous commensal microbes and their potential role in disease prevention or treatment. The rapidly increasing resistance to and failure of antibiotics in genitourinary infections provides a gap for health care providers in search of alternative strategies.

The instillation of Lactobacillus into the vagina may avert the ascension of uropathogens into the bladder through various mechanisms, including interference with pathogen adhesion, biofilm formation, invasion and growth, expression of virulence factors and modulation of the host immunity. In the future, other bacterial species commonly found in the urogenital tract of children, including microbes which have shown promise by antagonism of genitourinary pathogens (i.e., avirulent $E$. coli110), may be screened for applications to prevent cystitis or pyelonephritis. Numerous approaches have been pursued in order to evaluate Lactobacillus strains for UTI prophylaxis. These strategies include using a commercially available strain, a convenient but potentially low-yield strategy considering that many strains lack scientific documentation of efficacy in the urogenital tract. Other investigators have selected strains most commonly recovered from the vagina, a strategy that has been historically limited by knowledge gaps regarding commensal microbiology of the urogenital tract. The molecular taxonomy and microbiology of vaginal lactobacilli has advanced considerably in the past two decades. Instead of focusing on L. acidophilus as a primary probiotic candidate, scientific progress has contributed to our appreciation of newly considered species such as Lactobacillus crispatus, Lactobacillus iners, and Lactobacillus jensenii as predominant vaginal lactobacilli for probiotics investigations. As an example, $L$. iners is difficult to culture, but has demonstrated anti-biofilm effects in vitro ${ }^{111}$. Further studies with this microbe may support its future application as a probiotic alternative for the urogenital tract.

In the 1980s, a range of adhesion, competitive exclusion and growth inhibition assays were deemed most appropriate for determining probiotic properties of different Lactobacillus strains ${ }^{112}$. Isolates from dairy, poultry and human sources were speciated using biochemical methods and assayed against a range of uropathogenic bacteria. The studies demonstrated significant variation in anti-uropathogenic properties, even between strains of the same species 113. It is still unknown why L. rhamnosus strain GR-1, originally isolated from the distal urethra of a healthy woman, more readily colonizes the vagina and reduces the risk of UTIs, when compared to L. rhamnosus strain GG, which was originally isolated from feces ${ }^{114,} 115$. Presumably, strains isolated from the urogenital tract have an enhanced ability to survive, thrive and deliver beneficial functions in the genitourinary tract. These in vitro assay systems are still used by some investigators to select probiotic strains ${ }^{116-118}$, but few studies have shown a correlation between in vitro properties of candidate probiotics and efficacy in vivo. In brief, 
the ultimate proof of efficacy of probiotic strains depends on documented success in clinical trials. Clinical trials of intravaginal lactobacilli in adults have yielded mixed data ${ }^{119-121}$. To date, no studies have examined intravaginal lactobacilli administration in children, partly because this route is problematic for prepubescent girls. One study reported a modicum of success in a single subject with respect to delayed infection ${ }^{122}$. Additional and more comprehensive studies are needed to draw conclusions regarding the value of genitourinary administration of probiotics in prepubescent or adolescent girls.

Similar to the literature on intravaginal probiotics, clinical trials and questionnaire-based studies of orally administered probiotics in adults have yielded conflicting outcomes ${ }^{123-125}$. One publication showed that oral L. acidophilus DDS-1 may have been associated with prevention of recurrent UTI in a single patient ${ }^{126}$, but clearly this is not sufficiently rigorous. In another study, 585 premature infants ( $<33$ weeks or $<1,500 \mathrm{~g}$ ) were given milk supplemented with $6 \times 10^{9}$ colony-forming units of L. rhamnosus GG or placebo milk once per day from the first feed until discharge (mean 48 days) ${ }^{91}$. The frequency of UTI episodes was decreased (3.4 vs. $5.8 \%$ ), but the difference was not statistically significant. This study did show that the probiotic could be administered safely to newborns, although applications of live bacteria in neonates should be monitored in case of potential septic complications. A randomized clinical trial from Korea compared trimethoprim/sulfamethoxazole to oral L. acidophilus ATCC 4356 as prophylaxis for UTIs in 120 children with vesicoureteral reflux. ${ }^{127}$ The two strategies did not differ significantly in terms of UTI prevention with incidences of $18.3 \%$ in the probiotic prevention arm and $21.6 \%$ in the antibiotic prevention arm. However, these results strongly imply that probiotics could be deployed as alternatives to antibiotics with a possible reduction of complications due to antibiotics. More studies are needed to confirm these findings. In addition, it would be worthwhile to test combined antimicrobial and probiotic therapy, as a study by Anukam et al. has shown synergy of combined therapy in curing bacterial vaginosis $^{128}$.

Studies on urogenital tract-derived lactobacilli have shown that Lactobacillus strains GR-1 and $\mathrm{RC}-14$ are multi-functional and affect the host in complementary ways. The L. rhamnosus GR-1 strain produces the antimicrobial factor hydrogen peroxide. In addition, GR-1 has antiCandida activity and produces factors, such as auto-inducer 2 (AI-2) molecules, that modulate the growth and biofilm development of uropathogens 111,129 . The organism can dampen inflammatory responses, using IL-10 dependent and independent pathways, as shown in macrophage studies 130. Microarray experiments have shown that a single intravaginal dose of this GR-1 strain can upregulate host defense pathways (Kirjavainen et al., in press, International Journal of Probiotics), suggesting that its probiotic properties work through the host as well as directly on pathogens. The L. reuteri strain RC-14 produces elevated amounts of hydrogen peroxide, and this strain can elicit host secretion of mucin, a molecule which may act as a barrier to infection (G. Reid, unpublished data). Strain RC-14 also secretes biosurfactants that include a compound which interferes with adhesion by various uropathogens ${ }^{131}$, and a factor that down-regulates virulence factor expression in pathogens such as $S$. aureus ${ }^{132}$. Strain RC-14 also affects cell membrane components in E. coli, likely via generation of lactic acid. Of interest, RC-14 does not produce reuterin, the potent antimicrobial factor which may be critical for anti-pathogenic functions of other L. reuteri strains. Other anti-pathogenic compounds may be produced by strain RC-14 and account for its efficacy versus urogenital tract pathogens. Further studies of Lactobacillus strains GR-1 and RC-14 are necessary in order to identify key mechanisms involved in protection of the pediatric human host.

In conclusion, scant data on probiotic applications in children to prevent UTIs have been documented. A pilot clinical trial of Lactobacillus RC-14 and GR-1 is currently examining the potential reduction of bacteriuria in girls with spina bifida (M.H. and J.V., unpublished data). 
Initial results are promising but require completion of ongoing clinical investigations before such studies can be summarized and reported. Randomized, placebo-controlled, double blind clinical trials are planned to examine the potential utility of probiotics to prevent UTIs in girls. Probiotics-based strategies may diminish infections by reducing the numbers of infectious episodes per child or reducing the numbers of children with infections. If combinations of probiotics and antibiotics are efficacious, these agents may help cure infection with fewer side effects, reduce the problem of antibacterial resistance, and provide alternatives for pediatricians seeking to reduce the impact of recurrent infections.

\section{Probiotics for Pediatric Allergic or Atopic Disorders}

Beneficial microbes may modulate immune responses in the host and consequently may provide strategies for amelioration of pediatric immune-mediated disorders. Interestingly, many probiotic immunomodulatory effects are not only species-specific, but may be strainspecific as well. For example, some human breast milk-derived $L$. reuteri strains induce TNF production by human macrophages, whereas other strains inhibit TNF production through cJun, NF-kappa- $\beta$, and MAP kinase-dependent mechanisms ${ }^{133,134}$ (Figure 6). The immunomodulatory functions of commensal-derived probiotics have implications for the hygiene hypothesis. This hypothesis proposes that the increased incidence of chronic inflammatory disorders (e.g. allergic disorders, asthma, inflammatory bowel diseases) in the twentieth century is partly attributable to decreased early life exposure to commensal microbes and other organisms that have been intimately associated with humans throughout evolutionary history ${ }^{135}$. Such "old friends", including helminths and saprophytic mycobacteria, may be recognized by the innate immune system as harmless commensals that trigger immunoregulatory mechanisms. Such patterns of immune tolerance may result in the stimulation of regulatory dendritic cells that promote regulatory T-cell responses to "old friends" themselves and to "forbidden" target self-antigens of chronic inflammatory disorders. Specifically, probiotic strains may foster Th1 T cell responses and suppress Th2 pathways which are thought to enable many allergic and autoimmune diseases136. Ultimately, these indigenous microbial:host interactions may result in immune tolerance to self-antigens and exogenous airborne or food-derived antigens. Hence, sufficient exposure to beneficial microbes early in life may prevent subsequent development of immune-mediated disorders such as food allergies, asthma, and atopic dermatitis.

Many trials have been conducted to determine the role of probiotics in immune-mediated disorders such as allergies and atopic diseases. One placebo-controlled double blind study examined whether infants born to atopic mothers who ingested L. rhamnosus GG (LGG) and $B$. lactis $\mathrm{Bb} 12$ during pregnancy yielded favorable effects such as less severe or diminished incidence of allergy development. Indeed, this trial reported that the LGG/Bb12 strain combination lowered the risk of infant sensitization to environmental allergens ${ }^{137}$. A second randomized, double blind, placebo-controlled trial reported that infants exposed in utero (via maternal consumption of probiotics) to a synbiotic combination of prebiotic galactooligosaccharides and Lactobacillus rhamnosus GG, L. rhamnosus LC705(DSM 7061, B. breve Bb99(DSM 13692), and P. freudenreichii ssp. shermanii JS(DSM 7076) had a lower risk of developing atopic eczema, but these infants did not demonstrate a lower cumulative risk of allergic diseases ${ }^{138}$. However, the data for atopic disease prevention is not uniformly favorable. A randomized, double blind, placebo-controlled trial of LGG ingestion by pregnant women reported that this probiotic agent did not decrease the risk of atopic dermatitis in their children and was associated with an increased rate of recurrent episodes of wheezing bronchitis 139.

Multiple trials have studied the atopy-related effects of prebiotics and probiotics administered during infancy. Regimens that have been reported to ameliorate atopy include L. fermentum 
VRI-033 PCC ${ }^{140}$; L. rhamnosus GG (only in IgE-sensitized infants) ${ }^{141}$; and prebiotic mixtures of galacto- and long chain fructo-oligosaccharides 142, 143. Furthermore, LGG may alleviate atopic dermatitis in infants with atopic eczema and cow's milk allergy 144. Despite these positive studies, a number of trials have not shown atopy-related benefits to probiotic supplementation during infancy. Ineffective regimens that have been reported include LGG ${ }^{145-147}$; L. rhamnosus ATCC $53103{ }^{148}$; and L. acidophilus (LAVRI-A1) ${ }^{149}$.

Considering the mixed nature of results with probiotics in different clinical trials, it is difficult to render a verdict regarding the overall efficacy of probiotics to prevent or alleviate atopy. Ongoing trials such as the Trial of Infant Probiotic Supplementation (TIPS) may help clarify the role of probiotics in atopic diseases ${ }^{150}$. Beyond disease prevention, a key question remains whether probiotics may ameliorate atopic diseases if provided as part of a treatment regimen. A study of $L$ fermentum PCC reported that improvement in atopic dermatitis was associated with augmented Th1 interferon-gamma responses and altered responses to skin and enteric microbiota ${ }^{136}$. These findings are consistent with the hygiene hypothesis, but more studies are required to confirm these findings. Probiotics have also been administered to older children to treat atopy, and some studies have reported longer term disease-free follow-up periods in children exposed to probiotics as infants. Older children (1 to 13 years old) given $L$.

rhamnosus 19070-2 in combination with L. reuteri DSM 122460 featured improvements in atopic dermatitis, particularly those with a positive skin prick test response and increased $\operatorname{IgE}$ levels at baseline ${ }^{151}$. Atopic children older than 2 years of age who received L. rhamnosus Lcr35 plus a prebiotic preparation or prebiotics alone demonstrated improvement in dermatitis ${ }^{152}$. Finally, a 4 year follow-up study of children previously given $L$. rhamnosus GG during infancy reported that the risk of atopic eczema remained lower among those children that received probiotics versus placebo ${ }^{153}$. These findings suggest that some probiotics formulations yield persistent effects beyond the period of acute exposure. A conclusion of the Cochrane Database of Systematic Reviews is that the data suggest a possible role for probiotics in prevention of pediatric atopic dermatitis, but the data related to disease treatment with probiotics are unclear (www.cochrane.org) (Figure 5).

\section{Probiotics-Induced Sepsis}

Although probiotics seem to be promising strategies for prevention or treatment of a variety of pediatric diseases and are generally well-tolerated, several reports of probiotics-associated bacteremia and sepsis in children have been published ${ }^{154,155}$. Some of these studies included neonates or young infants who are susceptible to infections due to underdeveloped mucosal barriers and immature immune systems. Caution with probiotics strain selection, possibly by focusing on commensal-derived probiotics, and clinical study design, especially in neonates and infants, is warranted in pediatric practice. Given the large numbers of commercially available probiotic products that are mislabeled ${ }^{156-166}$, we advise that patients and their health care providers solely consider products which list not only specific bacterial species, but strain names, colony-forming units, non-probiotic ingredients, manufacturing standards, and high quality, peer-reviewed scientific studies of the probiotic strains in question.

\section{Summary}

Advances in the science of probiotics in the $21^{\text {st }}$ century will be fueled by human microbiome research and functional genomics of beneficial microbes. These indigenous microbes or "Old Friends" facilitate digestion, absorption of vitamins, development of robust immune responses, and suppression of pathogens. Two primary pipelines will serve as development strategies for new probiotics in human medicine. First, identification of genes responsible for key probiotic functions will enable derivation of genetically modified organisms (GMOs), or so called "designer strains", that will represent improved engineered alternatives to natural probiotic 
strains for specific biomedical applications. Secondly, candidate probiotic strains isolated from natural sources (human, animal or food) can be compared systematically by functional genomics and systems biology. Optimal or "ideal" natural probiotics can then be selected for specific probiotics applications in medicine. Many additional laboratory and clinical studies must be performed in the future to clarify mechanisms of probiosis and matching of specific probiotics or synbiotics with specific disease phenotypes in children. In summary, humans have utilized beneficial bacteria via the diet throughout human history. Investigator-initiated research and mega-science as in the Human Microbiome Project will drive accelerated development of probiotics for prevention and treatment of many pediatric disorders now and in the future.

\section{Acknowledgments}

The authors acknowledge Tiffany Morgan for her assistance with manuscript preparation. M.H. has research support from the Society of Pediatric Urology and the Spina Bifida Association. J.V. currently receives support from the National Institutes of Health (NIH) (NIDDK R01 DK065075; NCCAM R21 AT003482), the Office of Naval Research, and the Defense Advanced Research Projects Agency (DARPA).

\section{References}

1. Smit AF. The origin of interspersed repeats in the human genome. Curr Opin Genet Dev 1996;6:743. [PubMed: 8994846]

2. Bock M, Stoye JP. Endogenous retroviruses and the human germline. Curr Opin Genet Dev 2000;10:651. [PubMed: 11088016]

3. Tierno, PM. The secret life of germs. New York: 2001.

4. Paustian, T. The normal flora of humans. In: Paustian, T., editor. Microbiology and bacteriology: the world of microbes. Madison, WI: University of Wisconsin-Madison; 2006.

5. Rolfe RD. Interactions among microorganisms of the indigenous intestinal flora and their influence on the host. Rev Infect Dis 1984;6 (Suppl 1):S73. [PubMed: 6372040]

6. Nackerdien ZE. Perspectives on microbes as oncogenic infectious agents and implications for breast cancer. Med Hypotheses 2008;71:302. [PubMed: 18445513]

7. Wucherpfennig KW. Structural basis of molecular mimicry. J Autoimmun 2001;16:293. [PubMed: 11334495]

8. Barbara G, Stanghellini V, Brandi G, Cremon C, Di Nardo G, De Giorgio R, et al. Interactions between commensal bacteria and gut sensorimotor function in health and disease. Am J Gastroenterol 2005;100:2560. [PubMed: 16279914]

9. Quigley EM. Germs, gas and the gut; the evolving role of the enteric flora in IBS. Am J Gastroenterol 2006;101:334. [PubMed: 16454839]

10. Giaffer MH, Holdsworth CD, Duerden BI. The assessment of faecal flora in patients with inflammatory bowel disease by a simplified bacteriological technique. J Med Microbiol 1991;35:238. [PubMed: 1941994]

11. Nemet-Nejat, KR. Daily Life in Ancient Mesopotamia. Greenwood Publishing Group; 1998. p. 346

12. Farnsworth ER. Kefir -- a complex probiotic. Food Science and Technology Bulletin: Functional Foods 2005;2:1.

13. Versalovic, J.; Wilson, M. Therapeutic microbiology: probiotics and related strategies. 1. Washington, D.C: ASM Press; 2008. p. 403

14. Guidelines for the Evaluation of Probiotics in Food. London Ontario, Canada: Joint FAO/WHO Working Group on Drafting Guidelines for the Evaluation of Probiotics in Food; 2002. p. 1-11.

15. Eckburg PB, Bik EM, Bernstein CN, Purdom E, Dethlefsen L, Sargent M, et al. Diversity of the human intestinal microbial flora. Science 2005;308:1635. [PubMed: 15831718]

16. Gao Z, Tseng CH, Pei Z, Blaser MJ. Molecular analysis of human forearm superficial skin bacterial biota. Proc Natl Acad Sci U S A 2007;104:2927. [PubMed: 17293459] 
17. Swidsinski A, Weber J, Loening-Baucke V, Hale LP, Lochs H. Spatial organization and composition of the mucosal flora in patients with inflammatory bowel disease. J Clin Microbiol 2005;43:3380. [PubMed: 16000463]

18. Swidsinski A, Loening-Baucke V, Lochs H, Hale LP. Spatial organization of bacterial flora in normal and inflamed intestine: a fluorescence in situ hybridization study in mice. World J Gastroenterol 2005; 11:1131. [PubMed: 15754393]

19. Zoetendal EG, von Wright A, Vilpponen-Salmela T, Ben-Amor K, Akkermans AD, de Vos WM. Mucosa-associated bacteria in the human gastrointestinal tract are uniformly distributed along the colon and differ from the community recovered from feces. Appl Environ Microbiol 2002;68:3401. [PubMed: 12089021]

20. Turnbaugh PJ, Ley RE, Hamady M, Fraser-Liggett CM, Knight R, Gordon JI. The human microbiome project. Nature 2007;449:804. [PubMed: 17943116]

21. Palmer C, Bik EM, Digiulio DB, Relman DA, Brown PO. Development of the Human Infant Intestinal Microbiota. PLoS Biol 2007;5:e177. [PubMed: 17594176]

22. DiGiulio DB, Romero R, Amogan HP, Kusanovic JP, Bik EM, Gotsch F, et al. Microbial prevalence, diversity and abundance in amniotic fluid during preterm labor: a molecular and culture-based investigation. PLoS ONE 2008;3:e3056. [PubMed: 18725970]

23. Perez PF, Dore J, Leclerc M, Levenez F, Benyacoub J, Serrant P, et al. Bacterial imprinting of the neonatal immune system: lessons from maternal cells? Pediatrics 2007;119:e724. [PubMed: 17332189]

24. Metchnikoff, E. The prolongation of life: optimistic studies. New York and London: G.P. Putnam's Sons; 1908.

25. Fuller R. Probiotics in man and animals. J Appl Bacteriol 1989;66:365. [PubMed: 2666378]

26. Isolauri E, Sutas Y, Kankaanpaa P, Arvilommi H, Salminen S. Probiotics: effects on immunity. Am J Clin Nutr 2001;73:444S. [PubMed: 11157355]

27. Saavedra JM. Use of probiotics in pediatrics: rationale, mechanisms of action, and practical aspects. Nutr Clin Pract 2007;22:351. [PubMed: 17507735]

28. Gibson GR, Roberfroid MB. Dietary modulation of the human colonic microbiota: introducing the concept of prebiotics. J Nutr 1995;125:1401. [PubMed: 7782892]

29. Langhendries JP, Detry J, Van Hees J, Lamboray JM, Darimont J, Mozin MJ, et al. Effect of a fermented infant formula containing viable bifidobacteria on the fecal flora composition and $\mathrm{pH}$ of healthy full-term infants. J Pediatr Gastroenterol Nutr 1995;21:177. [PubMed: 7472904]

30. Valeur N, Engel P, Carbajal N, Connolly E, Ladefoged K. Colonization and immunomodulation by Lactobacillus reuteri ATCC 55730 in the human gastrointestinal tract. Appl Environ Microbiol 2004;70:1176. [PubMed: 14766603]

31. Brown JP. Role of gut bacterial flora in nutrition and health: a review of recent advances in bacteriological techniques, metabolism, and factors affecting flora composition. CRC Crit Rev Food Sci Nutr 1977;8:229. [PubMed: 338249]

32. Macfarlane S, Macfarlane GT, Cummings JH. Review article: prebiotics in the gastrointestinal tract. Aliment Pharmacol Ther 2006;24:701. [PubMed: 16918875]

33. Haarman M, Knol J. Quantitative real-time PCR analysis of fecal Lactobacillus species in infants receiving a prebiotic infant formula. Appl Environ Microbiol 2006;72:2359. [PubMed: 16597930]

34. de Bortoli N, Leonardi G, Ciancia E, Merlo A, Bellini M, Costa F, et al. Helicobacter pylori eradication: a randomized prospective study of triple therapy versus triple therapy plus lactoferrin and probiotics. Am J Gastroenterol 2007;102:951. [PubMed: 17313499]

35. Francavilla R, Lionetti E, Castellaneta SP, Magista AM, Maurogiovanni G, Bucci N, et al. Inhibition of Helicobacter pylori infection in humans by Lactobacillus reuteri ATCC 55730 and effect on eradication therapy: a pilot study. Helicobacter 2008;13:127. [PubMed: 18321302]

36. Myllyluoma E, Veijola L, Ahlroos T, Tynkkynen S, Kankuri E, Vapaatalo H, et al. Probiotic supplementation improves tolerance to Helicobacter pylori eradication therapy--a placebocontrolled, double-blind randomized pilot study. Aliment Pharmacol Ther 2005;21:1263. [PubMed: 15882248] 
37. Nista EC, Candelli M, Cremonini F, Cazzato IA, Zocco MA, Franceschi F, et al. Bacillus clausii therapy to reduce side-effects of anti-Helicobacter pylori treatment: randomized, double-blind, placebo controlled trial. Aliment Pharmacol Ther 2004;20:1181. [PubMed: 15569121]

38. Tursi A, Brandimarte G, Giorgetti GM, Modeo ME. Effect of Lactobacillus casei supplementation on the effectiveness and tolerability of a new second-line 10-day quadruple therapy after failure of a first attempt to cure Helicobacter pylori infection. Med Sci Monit 2004;10:CR662. [PubMed: 15567983]

39. Sykora J, Valeckova K, Amlerova J, Siala K, Dedek P, Watkins S, et al. Effects of a specially designed fermented milk product containing probiotic Lactobacillus casei DN-114 001 and the eradication of H. pylori in children: a prospective randomized double-blind study. J Clin Gastroenterol 2005;39:692. [PubMed: 16082279]

40. Weizman Z, Asli G, Alsheikh A. Effect of a probiotic infant formula on infections in child care centers: comparison of two probiotic agents. Pediatrics 2005;115:5. [PubMed: 15629974]

41. Shornikova AV, Casas IA, Isolauri E, Mykkanen H, Vesikari T. Lactobacillus reuteri as a therapeutic agent in acute diarrhea in young children. J Pediatr Gastroenterol Nutr 1997;24:399. [PubMed: 9144122]

42. Villarruel G, Rubio DM, Lopez F, Cintioni J, Gurevech R, Romero G, et al. Saccharomyces boulardii in acute childhood diarrhoea: a randomized, placebo-controlled study. Acta Paediatr 2007;96:538. [PubMed: 17306006]

43. Shornikova AV, Casas IA, Mykkanen H, Salo E, Vesikari T. Bacteriotherapy with Lactobacillus reuteri in rotavirus gastroenteritis. Pediatr Infect Dis J 1997;16:1103. [PubMed: 9427453]

44. Majamaa H, Isolauri E, Saxelin M, Vesikari T. Lactic acid bacteria in the treatment of acute rotavirus gastroenteritis. J Pediatr Gastroenterol Nutr 1995;20:333. [PubMed: 7608829]

45. Oberhelman RA, Gilman RH, Sheen P, Taylor DN, Black RE, Cabrera L, et al. A placebo-controlled trial of Lactobacillus GG to prevent diarrhea in undernourished Peruvian children. J Pediatr 1999;134:15. [PubMed: 9880443]

46. Salazar-Lindo E, Miranda-Langschwager P, Campos-Sanchez M, Chea-Woo E, Sack RB. Lactobacillus casei strain GG in the treatment of infants with acute watery diarrhea: a randomized, double-blind, placebo controlled clinical trial [ISRCTN67363048]. BMC Pediatr 2004;4:18. [PubMed: 15345099]

47. Rosenfeldt V, Michaelsen KF, Jakobsen M, Larsen CN, Moller PL, Tvede M, et al. Effect of probiotic Lactobacillus strains on acute diarrhea in a cohort of nonhospitalized children attending day-care centers. Pediatr Infect Dis J 2002;21:417. [PubMed: 12150179]

48. Arvola T, Laiho K, Torkkeli S, Mykkanen H, Salminen S, Maunula L, et al. Prophylactic Lactobacillus GG reduces antibiotic-associated diarrhea in children with respiratory infections: a randomized study. Pediatrics 1999;104:e64. [PubMed: 10545590]

49. Vanderhoof JA, Whitney DB, Antonson DL, Hanner TL, Lupo JV, Young RJ. Lactobacillus GG in the prevention of antibiotic-associated diarrhea in children. J Pediatr 1999;135:564. [PubMed: 10547243]

50. La Rosa M, Bottaro G, Gulino N, Gambuzza F, Di Forti F, Ini G, et al. Prevention of antibioticassociated diarrhea with Lactobacillus sporogens and fructo-oligosaccharides in children. A multicentric double-blind vs placebo study. Minerva Pediatr 2003;55:447. [PubMed: 14608267]

51. Can M, Besirbellioglu BA, Avci IY, Beker CM, Pahsa A. Prophylactic Saccharomyces boulardii in the prevention of antibiotic-associated diarrhea: a prospective study. Med Sci Monit 2006;12:PI19. [PubMed: 16572062]

52. Duman DG, Bor S, Ozutemiz O, Sahin T, Oguz D, Istan F, et al. Efficacy and safety of Saccharomyces boulardii in prevention of antibiotic-associated diarrhoea due to Helicobacterpylori eradication. Eur J Gastroenterol Hepatol 2005;17:1357. [PubMed: 16292090]

53. Erdeve O, Tiras U, Dallar Y. The probiotic effect of Saccharomyces boulardii in a pediatric age group. J Trop Pediatr 2004;50:234. [PubMed: 15357564]

54. Kotowska M, Albrecht P, Szajewska H. Saccharomyces boulardii in the prevention of antibioticassociated diarrhoea in children: a randomized double-blind placebo-controlled trial. Aliment Pharmacol Ther 2005;21:583. [PubMed: 15740542] 
55. McFarland LV, Surawicz CM, Greenberg RN, Elmer GW, Moyer KA, Melcher SA, et al. Prevention of beta-lactam-associated diarrhea by Saccharomyces boulardii compared with placebo. Am J Gastroenterol 1995;90:439. [PubMed: 7872284]

56. Surawicz CM, Elmer GW, Speelman P, McFarland LV, Chinn J, van Belle G. Prevention of antibioticassociated diarrhea by Saccharomyces boulardii: a prospective study. Gastroenterology 1989;96:981. [PubMed: 2494098]

57. McFarland LV, Surawicz CM, Greenberg RN, Fekety R, Elmer GW, Moyer KA, et al. A randomized placebo-controlled trial of Saccharomyces boulardii in combination with standard antibiotics for Clostridium difficile disease. Jama 1994;271:1913. [PubMed: 8201735]

58. Saps M, Pensabene L, Di Martino L, Staiano A, Wechsler J, Zheng X, et al. Post-infectious functional gastrointestinal disorders in children. J Pediatr 2008;152:812. [PubMed: 18492522]

59. Bradley HK, Wyatt GM, Bayliss CE, Hunter JO. Instability in the faecal flora of a patient suffering from food-related irritable bowel syndrome. J Med Microbiol 1987;23:29. [PubMed: 3820268]

60. Malinen E, Rinttila T, Kajander K, Matto J, Kassinen A, Krogius L, et al. Analysis of the fecal microbiota of irritable bowel syndrome patients and healthy controls with real-time PCR. Am J Gastroenterol 2005;100:373. [PubMed: 15667495]

61. Kajander K, Myllyluoma E, Rajilic-Stojanovic M, Kyronpalo S, Rasmussen M, Jarvenpaa S, et al. Clinical trial: multispecies probiotic supplementation alleviates the symptoms of irritable bowel syndrome and stabilizes intestinal microbiota. Aliment Pharmacol Ther 2008;27:48. [PubMed: 17919270]

62. Kajander K, Hatakka K, Poussa T, Farkkila M, Korpela R. A probiotic mixture alleviates symptoms in irritable bowel syndrome patients: a controlled 6-month intervention. Aliment Pharmacol Ther 2005;22:387. [PubMed: 16128676]

63. Kajander K, Krogius-Kurikka L, Rinttila T, Karjalainen H, Palva A, Korpela R. Effects of multispecies probiotic supplementation on intestinal microbiota in irritable bowel syndrome. Aliment Pharmacol Ther 2007;26:463. [PubMed: 17635381]

64. Nobaek S, Johansson ML, Molin G, Ahrne S, Jeppsson B. Alteration of intestinal microflora is associated with reduction in abdominal bloating and pain in patients with irritable bowel syndrome. Am J Gastroenterol 2000;95:1231. [PubMed: 10811333]

65. Fanigliulo L, Comparato G, Aragona G, Cavallaro L, Iori V, Maino M, et al. Role of gut microflora and probiotic effects in the irritable bowel syndrome. Acta Biomed 2006;77:85. [PubMed: 17172187]

66. O’Mahony L, McCarthy J, Kelly P, Hurley G, Luo F, Chen K, et al. Lactobacillus and bifidobacterium in irritable bowel syndrome: symptom responses and relationship to cytokine profiles. Gastroenterology 2005;128:541. [PubMed: 15765388]

67. Whorwell PJ, Altringer L, Morel J, Bond Y, Charbonneau D, O’Mahony L, et al. Efficacy of an encapsulated probiotic Bifidobacterium infantis 35624 in women with irritable bowel syndrome. Am J Gastroenterol 2006;101:1581. [PubMed: 16863564]

68. Sinn DH, Song JH, Kim HJ, Lee JH, Son HJ, Chang DK, et al. Therapeutic Effect of Lactobacillus acidophilus-SDC 2012, 2013 in Patients with Irritable Bowel Syndrome. Dig Dis Sci. 2008

69. Guyonnet D, Chassany O, Ducrotte P, Picard C, Mouret M, Mercier CH, et al. Effect of a fermented milk containing Bifidobacterium animalis DN-173 010 on the health-related quality of life and symptoms in irritable bowel syndrome in adults in primary care: a multicentre, randomized, doubleblind, controlled trial. Aliment Pharmacol Ther 2007;26:475. [PubMed: 17635382]

70. Colecchia A, Vestito A, La Rocca A, Pasqui F, Nikiforaki A, Festi D. Effect of a symbiotic preparation on the clinical manifestations of irritable bowel syndrome, constipation-variant. Results of an open, uncontrolled multicenter study. Minerva Gastroenterol Dietol 2006;52:349. [PubMed: 17108864]

71. Adler SN. The probiotic agent Escherichia coli M-17 has a healing effect in patients with IBS with proximal inflammation of the small bowel. Dig Liver Dis 2006;38:713. [PubMed: 16777498]

72. Kim HJ, Vazquez Roque MI, Camilleri M, Stephens D, Burton DD, Baxter K, et al. A randomized controlled trial of a probiotic combination VSL\# 3 and placebo in irritable bowel syndrome with bloating. Neurogastroenterol Motil 2005;17:687. [PubMed: 16185307]

73. Kim HJ, Camilleri M, McKinzie S, Lempke MB, Burton DD, Thomforde GM, et al. A randomized controlled trial of a probiotic, VSL\#3, on gut transit and symptoms in diarrhoea-predominant irritable bowel syndrome. Aliment Pharmacol Ther 2003;17:895. [PubMed: 12656692] 
74. Bittner AC, Croffut RM, Stranahan MC. Prescript-Assist probiotic-prebiotic treatment for irritable bowel syndrome: a methodologically oriented, 2-week, randomized, placebo-controlled, doubleblind clinical study. Clin Ther 2005;27:755. [PubMed: 16117982]

75. Drouault-Holowacz S, Bieuvelet S, Burckel A, Cazaubiel M, Dray X, Marteau P. A double blind randomized controlled trial of a probiotic combination in 100 patients with irritable bowel syndrome. Gastroenterol Clin Biol 2008;32:147. [PubMed: 18387426]

76. O'Sullivan MA, O'Morain CA. Bacterial supplementation in the irritable bowel syndrome. A randomised double-blind placebo-controlled crossover study. Dig Liver Dis 2000;32:294. [PubMed: 11515626]

77. Niv E, Naftali T, Hallak R, Vaisman N. The efficacy of Lactobacillus reuteri ATCC 55730 in the treatment of patients with irritable bowel syndrome--a double blind, placebo-controlled, randomized study. Clin Nutr 2005;24:925. [PubMed: 16051399]

78. Niedzielin K, Kordecki H, Birkenfeld B. A controlled, double-blind, randomized study on the efficacy of Lactobacillus plantarum $299 \mathrm{~V}$ in patients with irritable bowel syndrome. Eur J Gastroenterol Hepatol 2001;13:1143. [PubMed: 11711768]

79. Sen S, Mullan MM, Parker TJ, Woolner JT, Tarry SA, Hunter JO. Effect of Lactobacillus plantarum 299v on colonic fermentation and symptoms of irritable bowel syndrome. Dig Dis Sci 2002;47:2615. [PubMed: 12452404]

80. Bausserman M, Michail S. The use of Lactobacillus GG in irritable bowel syndrome in children: a double-blind randomized control trial. J Pediatr 2005;147:197. [PubMed: 16126049]

81. Gawronska A, Dziechciarz P, Horvath A, Szajewska H. A randomized double-blind placebocontrolled trial of Lactobacillus GG for abdominal pain disorders in children. Aliment Pharmacol Ther 2007;25:177. [PubMed: 17229242]

82. Rasquin A, Di Lorenzo C, Forbes D, Guiraldes E, Hyams JS, Staiano A, et al. Childhood functional gastrointestinal disorders: child/adolescent. Gastroenterology 2006;130:1527. [PubMed: 16678566]

83. Rousseaux C, Thuru X, Gelot A, Barnich N, Neut C, Dubuquoy L, et al. Lactobacillus acidophilus modulates intestinal pain and induces opioid and cannabinoid receptors. Nat Med 2007;13:35. [PubMed: 17159985]

84. Savino F, Pelle E, Palumeri E, Oggero R, Miniero R. Lactobacillus reuteri (American Type Culture Collection Strain 55730) versus simethicone in the treatment of infantile colic: a prospective randomized study. Pediatrics 2007;119:e124. [PubMed: 17200238]

85. Indrio F, Riezzo G, Raimondi F, Bisceglia M, Cavallo L, Francavilla R. The effects of probiotics on feeding tolerance, bowel habits, and gastrointestinal motility in preterm newborns. J Pediatr 2008;152:801. [PubMed: 18492520]

86. Stratiki Z, Costalos C, Sevastiadou S, Kastanidou O, Skouroliakou M, Giakoumatou A, et al. The effect of a bifidobacter supplemented bovine milk on intestinal permeability of preterm infants. Early Hum Dev 2007;83:575. [PubMed: 17229535]

87. Bin-Nun A, Bromiker R, Wilschanski M, Kaplan M, Rudensky B, Caplan M, et al. Oral probiotics prevent necrotizing enterocolitis in very low birth weight neonates. J Pediatr 2005; 147:192.

[PubMed: 16126048]

88. Lin HC, Su BH, Chen AC, Lin TW, Tsai CH, Yeh TF, et al. Oral probiotics reduce the incidence and severity of necrotizing enterocolitis in very low birth weight infants. Pediatrics 2005;115:1. [PubMed: 15629973]

89. Schmolzer G, Urlesberger B, Haim M, Kutschera J, Pichler G, Ritschl E, et al. Multi-modal approach to prophylaxis of necrotizing enterocolitis: clinical report and review of literature. Pediatr Surg Int 2006;22:573. [PubMed: 16775708]

90. Hoyos AB. Reduced incidence of necrotizing enterocolitis associated with enteral administration of Lactobacillus acidophilus and Bifidobacterium infantis to neonates in an intensive care unit. Int J Infect Dis 1999;3:197. [PubMed: 10575148]

91. Dani C, Biadaioli R, Bertini G, Martelli E, Rubaltelli FF. Probiotics feeding in prevention of urinary tract infection, bacterial sepsis and necrotizing enterocolitis in preterm infants. A prospective doubleblind study. Biol Neonate 2002;82:103. [PubMed: 12169832]

92. Karimi O, Pena AS, van Bodegraven AA. Probiotics (VSL\#3) in arthralgia in patients with ulcerative colitis and Crohn's disease: a pilot study. Drugs Today (Barc) 2005;41:453. [PubMed: 16193098] 
93. Bibiloni R, Fedorak RN, Tannock GW, Madsen KL, Gionchetti P, Campieri M, et al. VSL\#3 probiotic-mixture induces remission in patients with active ulcerative colitis. Am J Gastroenterol 2005;100:1539. [PubMed: 15984978]

94. Gionchetti P, Rizzello F, Morselli C, Poggioli G, Tambasco R, Calabrese C, et al. High-dose probiotics for the treatment of active pouchitis. Dis Colon Rectum 2007;50:2075. [PubMed: 17934776]

95. Kuhbacher T, Ott SJ, Helwig U, Mimura T, Rizzello F, Kleessen B, et al. Bacterial and fungal microbiota in relation to probiotic therapy (VSL\#3) in pouchitis. Gut 2006;55:833. [PubMed: 16401690]

96. Tursi A, Brandimarte G, Giorgetti GM, Forti G, Modeo ME, Gigliobianco A. Low-dose balsalazide plus a high-potency probiotic preparation is more effective than balsalazide alone or mesalazine in the treatment of acute mild-to-moderate ulcerative colitis. Med Sci Monit 2004;10:PI126. [PubMed: 15507864]

97. Gionchetti P, Rizzello F, Helwig U, Venturi A, Lammers KM, Brigidi P, et al. Prophylaxis of pouchitis onset with probiotic therapy: a double-blind, placebo-controlled trial. Gastroenterology 2003;124:1202. [PubMed: 12730861]

98. Gionchetti P, Rizzello F, Venturi A, Brigidi P, Matteuzzi D, Bazzocchi G, et al. Oral bacteriotherapy as maintenance treatment in patients with chronic pouchitis: a double-blind, placebo-controlled trial. Gastroenterology 2000;119:305. [PubMed: 10930365]

99. Wildt S, Munck LK, Vinter-Jensen L, Hanse BF, Nordgaard-Lassen I, Christensen S, et al. Probiotic treatment of collagenous colitis: a randomized, double-blind, placebo-controlled trial with Lactobacillus acidophilus and Bifidobacterium animalis subsp. Lactis. Inflamm Bowel Dis 2006;12:395. [PubMed: 16670529]

100. Delia P, Sansotta G, Donato V, Frosina P, Messina G, De Renzis C, et al. Use of probiotics for prevention of radiation-induced diarrhea. World J Gastroenterol 2007;13:912. [PubMed: 17352022]

101. Kalliomaki M, Collado MC, Salminen S, Isolauri E. Early differences in fecal microbiota composition in children may predict overweight. Am J Clin Nutr 2008;87:534. [PubMed: 18326589]

102. Turnbaugh PJ, Backhed F, Fulton L, Gordon JI. Diet-induced obesity is linked to marked but reversible alterations in the mouse distal gut microbiome. Cell Host Microbe 2008;3:213. [PubMed: 18407065]

103. Lee K, Paek K, Lee HY, Park JH, Lee Y. Antiobesity effect of trans-10,cis-12-conjugated linoleic acid-producing Lactobacillus plantarum PL62 on diet-induced obese mice. J Appl Microbiol 2007;103:1140. [PubMed: 17897219]

104. Bruce AW, Chadwick P, Hassan A, VanCott GF. Recurrent urethritis in women. Can Med Assoc J 1973;108:973. [PubMed: 4633489]

105. Bruce AW, Reid G. Probiotics and the urologist. Can J Urol 2003;10:1785. [PubMed: 12773227]

106. Kelly MC, Mequio MJ, Pybus V. Inhibition of vaginal lactobacilli by a bacteriocin-like inhibitor produced by Enterococcus faecium 62-6: potential significance for bacterial vaginosis. Infect Dis Obstet Gynecol 2003;11:147. [PubMed: 15022875]

107. Bacheller CD, Bernstein JM. Urinary tract infections. Med Clin North Am 1997;81:719. [PubMed: 9167654]

108. Gower PR, Roberts AP. Qualitative assessment of midstream urine cultures in the detection of bacteriuria. Clin Nephrol 1975;3:10. [PubMed: 805012]

109. Seno Y, Kariyama R, Mitsuhata R, Monden K, Kumon H. Clinical implications of biofilm formation by Enterococcus faecalis in the urinary tract. Acta Med Okayama 2005;59:79. [PubMed: 16049560]

110. Hull R, Rudy D, Donovan W, Svanborg C, Wieser I, Stewart C, et al. Urinary tract infection prophylaxis using Escherichia coli 83972 in spinal cord injured patients. J Urol 2000;163:872. [PubMed: 10687996]

111. Saunders S, Bocking A, Challis J, Reid G. Effect of Lactobacillus challenge on Gardnerella vaginalis biofilms. Colloids Surf B Biointerfaces 2007;55:138. [PubMed: 17234391]

112. Chan RC, Bruce AW, Reid G. Adherence of cervical, vaginal and distal urethral normal microbial flora to human uroepithelial cells and the inhibition of adherence of gram-negative uropathogens by competitive exclusion. J Urol 1984;131:596. [PubMed: 6422061] 
113. Reid G, Cook RL, Bruce AW. Examination of strains of lactobacilli for properties that may influence bacterial interference in the urinary tract. J Urol 1987;138:330. [PubMed: 3599250]

114. Cadieux P, Burton J, Gardiner G, Braunstein I, Bruce AW, Kang CY, et al. Lactobacillus strains and vaginal ecology. Jama 2002;287:1940. [PubMed: 11960535]

115. Colodner R, Edelstein H, Chazan B, Raz R. Vaginal colonization by orally administered Lactobacillus rhamnosus GG. Isr Med Assoc J 2003;5:767. [PubMed: 14650098]

116. Ocana VS, Elena Nader-Macias M. Production of antimicrobial substances by lactic acid bacteria II: screening bacteriocin-producing strains with probiotic purposes and characterization of a Lactobacillus bacteriocin. Methods Mol Biol 2004;268:347. [PubMed: 15156045]

117. Osset J, Bartolome RM, Garcia E, Andreu A. Assessment of the capacity of Lactobacillus to inhibit the growth of uropathogens and block their adhesion to vaginal epithelial cells. J Infect Dis 2001;183:485. [PubMed: 11133381]

118. Strus M, Kucharska A, Kukla G, Brzychczy-Wloch M, Maresz K, Heczko PB. The in vitro activity of vaginal Lactobacillus with probiotic properties against Candida. Infect Dis Obstet Gynecol 2005;13:69. [PubMed: 16011996]

119. Baerheim A, Larsen E, Digranes A. Vaginal application of lactobacilli in the prophylaxis of recurrent lower urinary tract infection in women. Scand J Prim Health Care 1994;12:239. [PubMed: 7863140]

120. Reid G, Bruce AW, Taylor M. Influence of three-day antimicrobial therapy and lactobacillus vaginal suppositories on recurrence of urinary tract infections. Clin Ther 1992;14:11. [PubMed: 1576619]

121. Reid G, Bruce AW, Taylor M. Instillation of Lactobacillus and stimulation of indigenous organisms to prevent recurrence of urinary tract infections. Microecol Ther 1995;23:32.

122. Bruce AW, Reid G. Intravaginal instillation of lactobacilli for prevention of recurrent urinary tract infections. Can J Microbiol 1988;34:339. [PubMed: 3138016]

123. Kontiokari T, Laitinen J, Jarvi L, Pokka T, Sundqvist K, Uhari M. Dietary factors protecting women from urinary tract infection. Am J Clin Nutr 2003;77:600. [PubMed: 12600849]

124. Kontiokari T, Sundqvist K, Nuutinen M, Pokka T, Koskela M, Uhari M. Randomised trial of cranberry-lingonberry juice and Lactobacillus GG drink for the prevention of urinary tract infections in women. Bmj 2001;322:1571. [PubMed: 11431298]

125. Reid G, Charbonneau D, Erb J, Kochanowski B, Beuerman D, Poehner R, et al. Oral use of Lactobacillus rhamnosus GR-1 and L. fermentum RC-14 significantly alters vaginal flora: randomized, placebo-controlled trial in 64 healthy women. FEMS Immunol Med Microbiol 2003;35:131. [PubMed: 12628548]

126. Gerasimov SV. Probiotic prophylaxis in pediatric recurrent urinary tract infections. Clin Pediatr (Phila) 2004;43:95. [PubMed: 14968899]

127. Lee SJ, Shim YH, Cho SJ, Lee JW. Probiotics prophylaxis in children with persistent primary vesicoureteral reflux. Pediatr Nephrol 2007;22:1315. [PubMed: 17530295]

128. Anukam K, Osazuwa E, Ahonkhai I, Ngwu M, Osemene G, Bruce AW, et al. Augmentation of antimicrobial metronidazole therapy of bacterial vaginosis with oral probiotic Lactobacillus rhamnosus GR-1 and Lactobacillus reuteri RC-14: randomized, double-blind, placebo controlled trial. Microbes Infect 2006;8:1450. [PubMed: 16697231]

129. Reid G, Kim SO, Kohler GA. Selecting, testing and understanding probiotic microorganisms. FEMS Immunol Med Microbiol 2006;46:149. [PubMed: 16487295]

130. Kim SO, Sheikh HI, Ha SD, Martins A, Reid G. G-CSF-mediated inhibition of JNK is a key mechanism for Lactobacillus rhamnosus-induced suppression of TNF production in macrophages. Cell Microbiol 2006;8:1958. [PubMed: 16889627]

131. Velraeds MM, van de Belt-Gritter B, van der Mei HC, Reid G, Busscher HJ. Interference in initial adhesion of uropathogenic bacteria and yeasts to silicone rubber by a Lactobacillus acidophilus biosurfactant. J Med Microbiol 1998;47:1081. [PubMed: 9856644]

132. Laughton, J.; Devillard, E.; Heinrichs, DE.; Reid, G.; McCormick, JK. Cell-cell communication in Gram-positive bacteria: Inhibition of Staphylococcus aureus exotoxin expression by Lactobacillus reuteri. American Society for Microbiology Conference on cell-cell communication; Banff, Alberta. 2004. 
133. Iyer C, Kosters A, Sethi G, Kunnumakkara AB, Aggarwal BB, Versalovic J. Probiotic Lactobacillus reuteri promotes TNF-induced apoptosis in human myeloid leukemia-derived cells by modulation of NF-kappaB and MAPK signalling. Cell Microbiol 2008;10:1442. [PubMed: 18331465]

134. Lin YP, Thibodeaux CH, Pena JA, Ferry GD, Versalovic J. Probiotic Lactobacillus reuteri suppress proinflammatory cytokines via c-Jun. Inflamm Bowel Dis 2008;14:1068. [PubMed: 18425802]

135. Rook GA. The hygiene hypothesis and the increasing prevalence of chronic inflammatory disorders. Trans R Soc Trop Med Hyg 2007;101:1072. [PubMed: 17619029]

136. Prescott SL, Dunstan JA, Hale J, Breckler L, Lehmann H, Weston S, et al. Clinical effects of probiotics are associated with increased interferon-gamma responses in very young children with atopic dermatitis. Clin Exp Allergy 2005;35:1557. [PubMed: 16393321]

137. Huurre A, Laitinen K, Rautava S, Korkeamaki M, Isolauri E. Impact of maternal atopy and probiotic supplementation during pregnancy on infant sensitization: a double-blind placebo-controlled study. Clin Exp Allergy. 2008

138. Kukkonen K, Savilahti E, Haahtela T, Juntunen-Backman K, Korpela R, Poussa T, et al. Probiotics and prebiotic galacto-oligosaccharides in the prevention of allergic diseases: a randomized, doubleblind, placebo-controlled trial. J Allergy Clin Immunol 2007;119:192. [PubMed: 17208601]

139. Kopp MV, Hennemuth I, Heinzmann A, Urbanek R. Randomized, double-blind, placebo-controlled trial of probiotics for primary prevention: no clinical effects of Lactobacillus GG supplementation. Pediatrics 2008;121:e850. [PubMed: 18332075]

140. Weston S, Halbert A, Richmond P, Prescott SL. Effects of probiotics on atopic dermatitis: a randomised controlled trial. Arch Dis Child 2005;90:892. [PubMed: 15863468]

141. Viljanen M, Savilahti E, Haahtela T, Juntunen-Backman K, Korpela R, Poussa T, et al. Probiotics in the treatment of atopic eczema/dermatitis syndrome in infants: a double-blind placebo-controlled trial. Allergy 2005;60:494. [PubMed: 15727582]

142. Moro G, Arslanoglu S, Stahl B, Jelinek J, Wahn U, Boehm G. A mixture of prebiotic oligosaccharides reduces the incidence of atopic dermatitis during the first six months of age. Arch Dis Child 2006;91:814. [PubMed: 16873437]

143. Arslanoglu S, Moro GE, Schmitt J, Tandoi L, Rizzardi S, Boehm G. Early dietary intervention with a mixture of prebiotic oligosaccharides reduces the incidence of allergic manifestations and infections during the first two years of life. J Nutr 2008;138:1091. [PubMed: 18492839]

144. Majamaa H, Isolauri E. Probiotics: a novel approach in the management of food allergy. J Allergy Clin Immunol 1997;99:179. [PubMed: 9042042]

145. Gruber C, Wendt M, Sulser C, Lau S, Kulig M, Wahn U, et al. Randomized, placebo-controlled trial of Lactobacillus rhamnosus GG as treatment of atopic dermatitis in infancy. Allergy 2007;62:1270. [PubMed: 17919141]

146. Brouwer ML, Wolt-Plompen SA, Dubois AE, van der Heide S, Jansen DF, Hoijer MA, et al. No effects of probiotics on atopic dermatitis in infancy: a randomized placebo-controlled trial. Clin Exp Allergy 2006;36:899. [PubMed: 16839405]

147. Folster-Holst R, Muller F, Schnopp N, Abeck D, Kreiselmaier I, Lenz T, et al. Prospective, randomized controlled trial on Lactobacillus rhamnosus in infants with moderate to severe atopic dermatitis. Br J Dermatol 2006;155:1256. [PubMed: 17107398]

148. Helin T, Haahtela S, Haahtela T. No effect of oral treatment with an intestinal bacterial strain, Lactobacillus rhamnosus (ATCC 53103), on birch-pollen allergy: a placebo-controlled doubleblind study. Allergy 2002;57:243. [PubMed: 11906339]

149. Taylor AL, Dunstan JA, Prescott SL. Probiotic supplementation for the first 6 months of life fails to reduce the risk of atopic dermatitis and increases the risk of allergen sensitization in high-risk children: a randomized controlled trial. J Allergy Clin Immunol 2007;119:184. [PubMed: 17208600]

150. Cabana MD, McKean M, Wong AR, Chao C, Caughey AB. Examining the hygiene hypothesis: the Trial of Infant Probiotic Supplementation. Paediatr Perinat Epidemiol 2007;21 (Suppl 3):23. [PubMed: 17935572]

151. Rosenfeldt V, Benfeldt E, Nielsen SD, Michaelsen KF, Jeppesen DL, Valerius NH, et al. Effect of probiotic Lactobacillus strains in children with atopic dermatitis. J Allergy Clin Immunol 2003;111:389. [PubMed: 12589361] 
152. Passeron T, Lacour JP, Fontas E, Ortonne JP. Prebiotics and synbiotics: two promising approaches for the treatment of atopic dermatitis in children above 2 years. Allergy 2006;61:431. [PubMed: 16512804]

153. Kalliomaki M, Salminen S, Poussa T, Arvilommi H, Isolauri E. Probiotics and prevention of atopic disease: 4-year follow-up of a randomised placebo-controlled trial. Lancet 2003;361:1869. [PubMed: 12788576]

154. Salminen MK, Tynkkynen S, Rautelin H, Saxelin M, Vaara M, Ruutu P, et al. Lactobacillus bacteremia during a rapid increase in probiotic use of Lactobacillus rhamnosus GG in Finland. Clin Infect Dis 2002;35:1155. [PubMed: 12410474]

155. Land MH, Rouster-Stevens K, Woods CR, Cannon ML, Cnota J, Shetty AK. Lactobacillus sepsis associated with probiotic therapy. Pediatrics 2005;115:178. [PubMed: 15629999]

156. Coeuret V, Gueguen M, Vernoux JP. Numbers and strains of lactobacilli in some probiotic products. Int J Food Microbiol 2004;97:147. [PubMed: 15541801]

157. Drisko J, Bischoff B, Giles C, Adelson M, Rao RV, McCallum R. Evaluation of five probiotic products for label claims by DNA extraction and polymerase chain reaction analysis. Dig Dis Sci 2005;50:1113. [PubMed: 15986864]

158. Elliot E, Teversham K. An evaluation of nine probiotics available in South Africa, August 2003. S Afr Med J 2004;94:121. [PubMed: 15034991]

159. Hamilton-Miller JM, Shah S, Winkler JT. Public health issues arising from microbiological and labelling quality of foods and supplements containing probiotic microorganisms. Public Health Nutr 1999;2:223. [PubMed: 10447251]

160. Huys G, Vancanneyt M, D’Haene K, Vankerckhoven V, Goossens H, Swings J. Accuracy of species identity of commercial bacterial cultures intended for probiotic or nutritional use. Res Microbiol 2006;157:803. [PubMed: 16919915]

161. Szajewska H, Fordymacka A, Bardowski J, Gorecki RK, Mrukowicz JZ, Banaszkiewicz A. Microbiological and genetic analysis of probiotic products licensed for medicinal purposes. Med Sci Monit 2004;10:BR346. [PubMed: 15328480]

162. Temmerman R, Scheirlinck I, Huys G, Swings J. Culture-independent analysis of probiotic products by denaturing gradient gel electrophoresis. Appl Environ Microbiol 2003;69:220. [PubMed: 12513998]

163. Weese JS. Microbiologic evaluation of commercial probiotics. J Am Vet Med Assoc 2002;220:794. [PubMed: 11918274]

164. Weese JS. Evaluation of deficiencies in labeling of commercial probiotics. Can Vet J 2003;44:982. [PubMed: 14703084]

165. Drago L, De Vecchi E, Nicola L, Colombo A, Gismondo MR. Microbiological evaluation of commercial probiotic products available in Italy. J Chemother 2004;16:463. [PubMed: 15565913]

166. Masco L, Huys G, De Brandt E, Temmerman R, Swings J. Culture-dependent and cultureindependent qualitative analysis of probiotic products claimed to contain bifidobacteria. Int J Food Microbiol 2005;102:221. [PubMed: 15992621] 

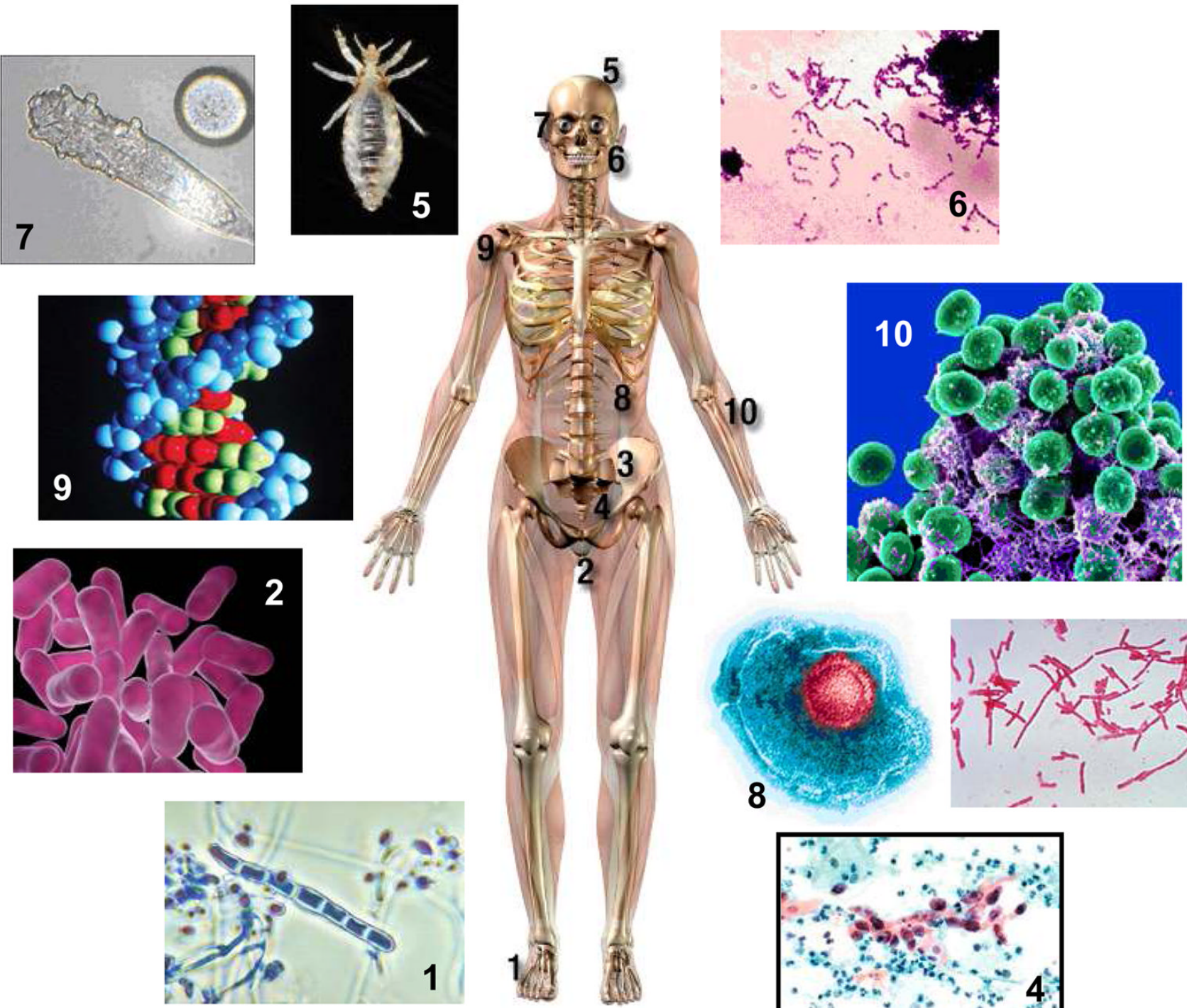

Figure 1. The human super-organism

Adapted from Glausiusz, Discover Magazine, June 2007, as well as images courtesy of the National Institutes of Health, National Cancer Institute, Centers for Disease Control, and Wikipedia. This figure depicts different microbes and other organisms that have been intimately associated with humans as commensals or potential pathogens. The numbers correspond to images of organisms and approximate anatomic locations where these organisms may reside on the human body. 1. Trichophyton and Epidermophyton are filamentous, parasitic microbes that cause athlete's foot. 2. Vaginal microbiota, mostly Lactobacillus species secrete lactic acid and other antimicrobial compounds that prevent pathogen overgrowth. 3. More than 500 species of bacteria, weighing approximately 3.3 pounds in the average human adult, live inside the gastrointestinal tract. 4. More than 100 strains of human papillomavirus (HPV) can infect humans, causing a variety of warts from the common wart to plantar and flat warts. $\mathbf{5}$. Pediculus humanus capitis, the head louse, may have co-evolved with recent $H$. sapiens. 6. Oral Streptococcus species form biofilms that may be 300-500 cells in thickness on the surfaces of unbrushed teeth. 7. Demodex mites inhabit the follicles of the eyelashes and infest about 20 percent of people under the age of 20. 8. After initial infection with the varicella-zoster virus (chickenpox), the virus remains dormant in nerve ganglia and may cause disease due to re- 
activation later in life. 9. Approximately $1 / 12$ of the human genome consists of DNA from fossil viruses that infected human ancestors millions of years ago. 10. Prevalent bacterial genera on the human skin include Streptococcus, Staphylococcus, and Corynebacterium. 


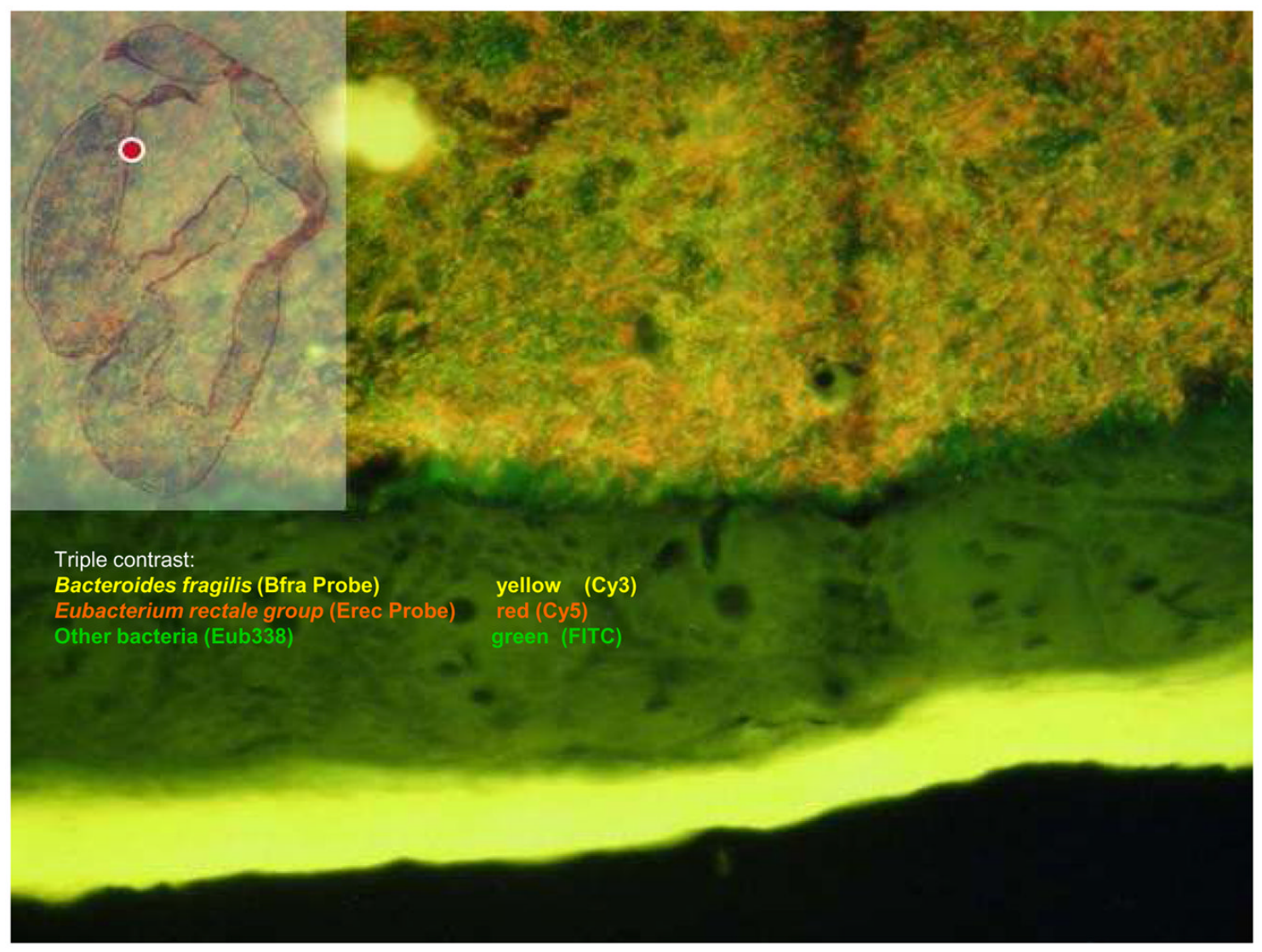

Figure 2. Colonic microbial architecture: differential distribution of bacteria

Adapted from Swidsinki et al. (www.charite.de/arbmkl/einzelne_seiten_der_maus/0.htm; with permission). FISH staining of the colonic wall microbiota reveals discrete zones for different bacterial species. Yellow staining designates the $B$. fragilis-specific Bfra probe conjugated to $\mathrm{Cy} 3$ dye, red staining designates the E. rectale-specific Erec probe conjugated to Cy5 dye, and green staining designates the Eubacteria-specific Eub388 probe conjugated to FITC dye. 
6

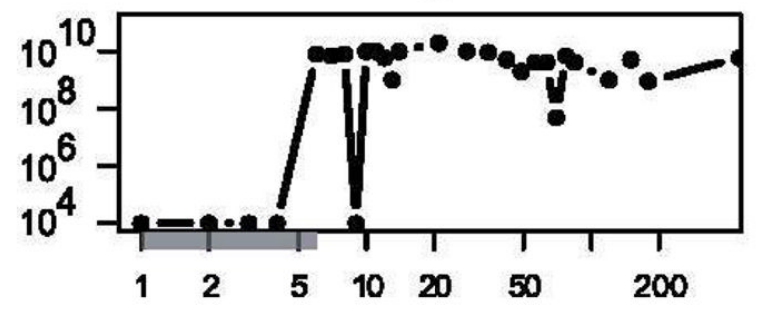

Antibiotic suppression of neonatal colonization
12

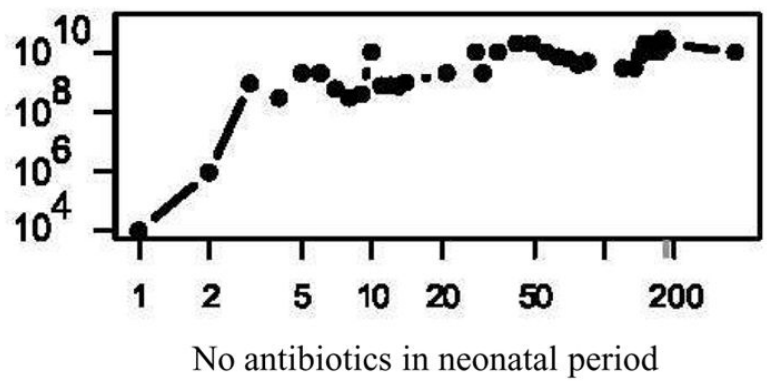

8

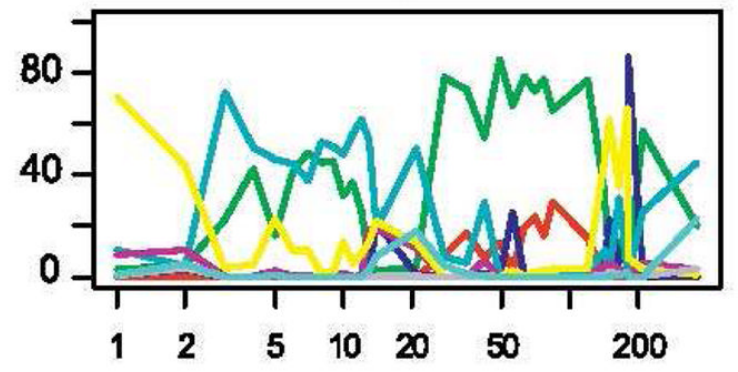

Figure 3. Different bacterial colonization pattterns in the intestines (feces) in human infants Adapted from Palmer et al. PLOS Biol 2007;5(7):e177. Upper panels show bacterial abundance by TaqMan real-time PCR with universal bacterial primers. Estimated rRNA gene copies per gram of feces (y-axis) are plotted as a function of days of life (x-axis). The lower panels show taxonomic groups with mean (normalized) relative abundance greater than $1 \%$. The $\mathrm{x}$-axis indicates days since birth and is shown on a log scale, and the $y$-axis shows estimated (normalized) relative abundance based on bacterial microarray data. 


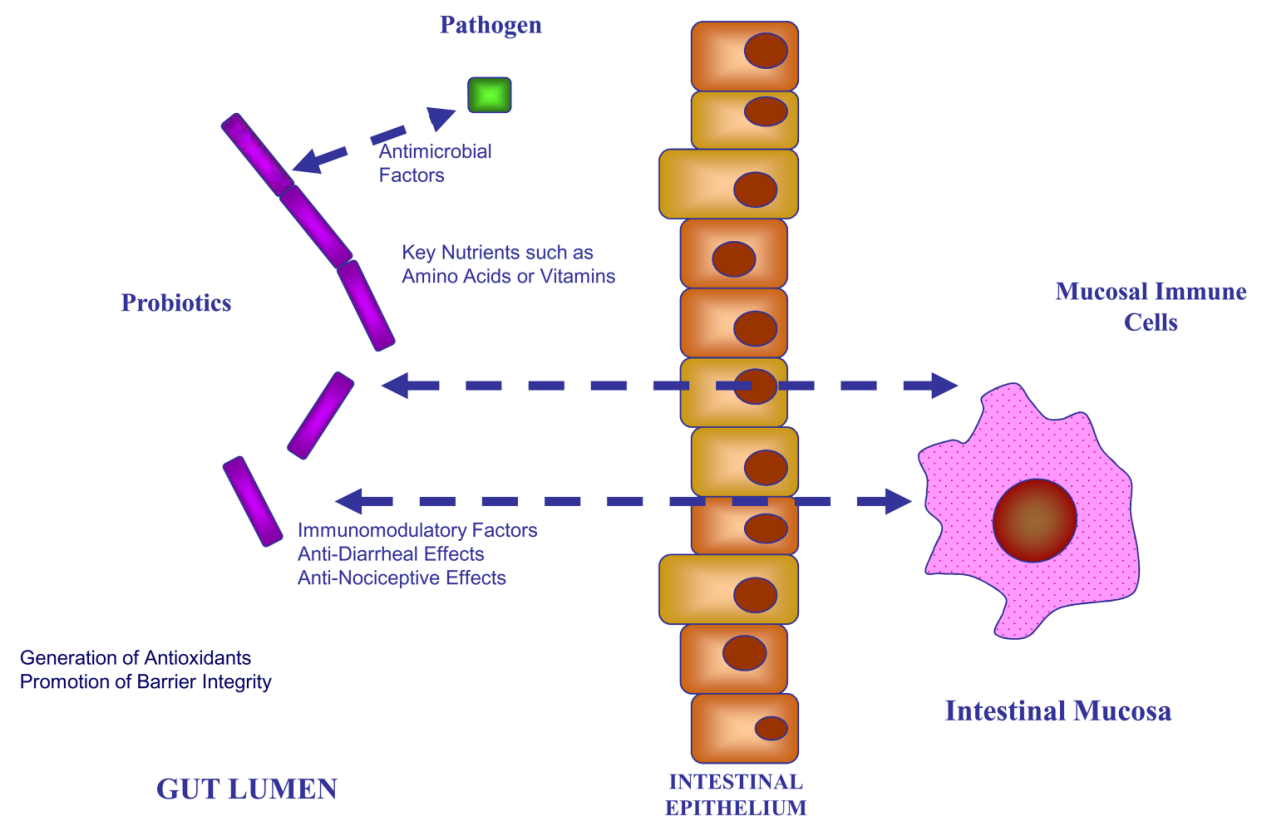

Figure 4. Beneficial roles for probiotics in the mammalian intestine

Probiotics (purple rod-shaped cells) may secrete various factors (depicted by arrows) that confer beneficial effects on the host. These effects include the production of key nutrients, antimicrobial factors, immunomodulatory factors and other compounds with possible effects listed in this figure. Probiotics may co-exist and suppress bacterial pathogens and interact intimately with the intestinal epithelium and immune cells (depicted on right side of slide). 


\section{Crohn Disease No benefit \\ Ulcerative Colitis \\ Maintenance of remission \\ Necrotizing Enterocolitis \\ Reduction of severe NEC and mortality \\ Pediatric Antibiotic-Associated Diarrhea \\ Promising but intention-to-treat analysis shows no significant benefit
Allergies and Food Hypersensivity in Infants
No benefit
Acute Gastroenteritis in Children
Effective for disease prevention
May reduce duration of acute disease
Pediatric Atopic Dermatitis
Possible role in disease prevention, not treatment

Figure 5. Probiotics and meta-analyses

Based on the best available evidence, the Cochrane Database has published assessments of the strength of evidence for use of probiotics in gastrointestinal and atopy-related diseases. Source: Cochrane Database of Systematic Reviews. 


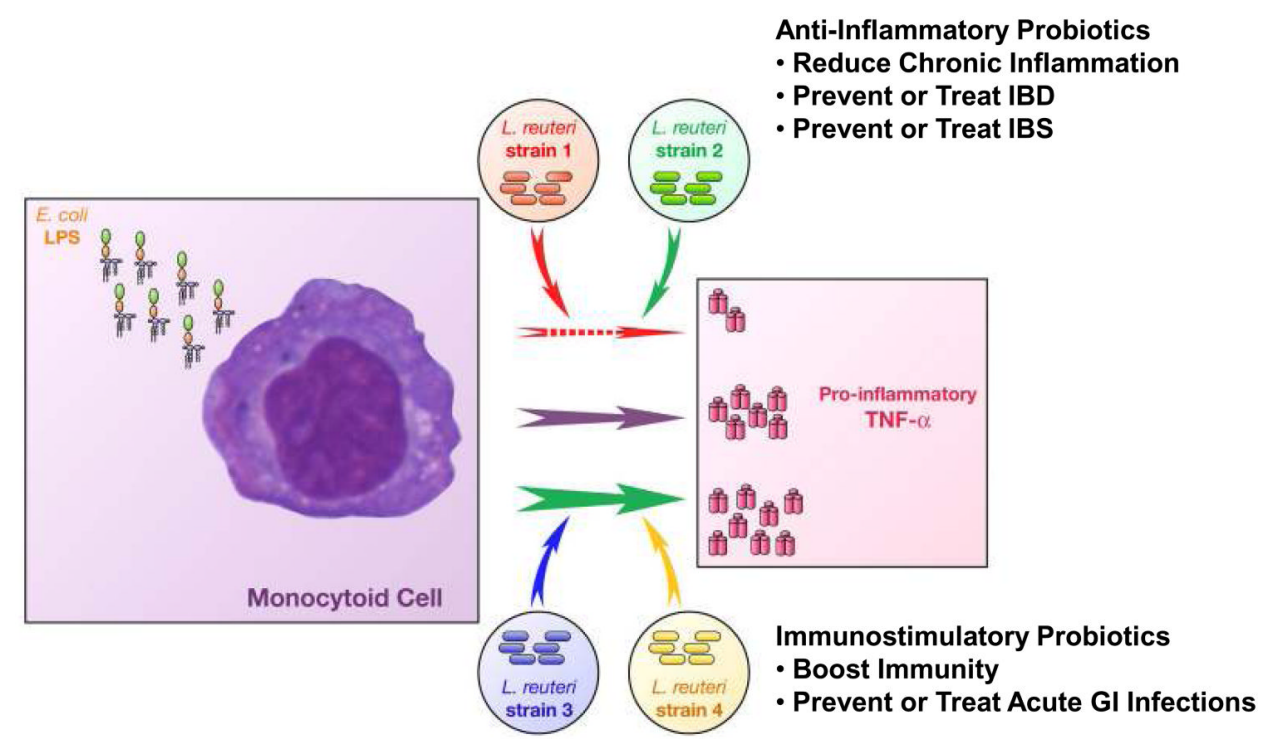

Figure 6. Probiotic-mediated modulation of innate immunity

Some probiotic strains promote TNF production by monocytes and are considered immunostimulatory (arrows representing two L. reuteri strains), whereas other strains, even within the same species, may inhibit TNF production by monocytes and are considered antiinflammatory (arrows representing two L. reuteri strains). These probiotic effects may be exploited to alleviate inflammatory diseases as well as prevent and treat infections. 